\title{
Excitation and \\ Deexcitation of Benzene
}

\author{
R. B. CUNDALL \\ Department of Chemistry and Applied Chemistry \\ University of Salford, United Kingdom \\ and \\ D. A. ROBINSON \\ Department of Chemistry, University of Botswana \\ Lesotho, and Swaziland, Gaborone, Botswana \\ and \\ L. C. PEREIRA \\ Department of Physics, University of Minho \\ Portuga 1
}

\section{CONTENTS}

I. Introduction. . . . . . . . . . . . . . . 148

II. The Nature of the Lower Excited States of Benzene . 148

III. Transitions Between Lower Energy States . . . . . . 152

A. Excitation from the ${ }^{1} \mathrm{~A}_{1 \mathrm{~g}}$ State. . . . . . . . 153

B. Emission to the ${ }^{\mathrm{A}_{1 \mathrm{~g}}}$ state. . . . . . . . . 153

C. Transitions Between Excited Singlet and

Triplet States. . . . . . . . . . . 154

IV. Excited State Geometry. . . . . . . . . . . . 154

v. The Influence of the Environment on Electronic

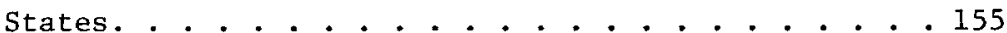

VI. The $\mathrm{S}_{1} \leftrightarrow \mathrm{S}_{0}$ Radiative Transition . . . . . . . 161

VII. The $S_{1} \leftrightarrow$ Triplet Radiationless Transition. . . . . 174

VIII. The $\mathrm{S}_{1} \rightarrow \mathrm{S}_{\mathrm{o}}$ Radiationless Transition . . . . • • 177

IX. The $\mathrm{T}_{1} \rightarrow \mathrm{S}_{\mathrm{o}}$ Phosphorescence Transition . . . . . 181

$\mathrm{X}$. The $\mathrm{T}_{1} \rightarrow \mathrm{S}_{\mathrm{o}}$ Radiationless Transition . . . . . . 189

XI. Transitions from Higher ( $n>1$ ) Excited States. . . 192 
XII. Relevant Photochemical Reactions of Excited

States of Benzene . . . . . . . . . . . . . 194

XIII. Benzene Excimer . . . . . . . . . . . . 196

XIV. Conclusion. . . . . . . . ........ . 201

Acknowledgements . . . . . . . . . . . . . . 201

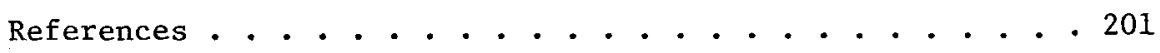

\section{INTRODUCTION}

A large amount of spectroscopic data are now available for benzene, providing much information on photophysics and photochemistry properties of the lowest excited states of this molecule. Nevertheless the nature of the various radiative and nonradiative transitions involved in the deexcitation of the first excited states is far from being completely understood.

This work reviews the photophysics and relevant photochemistry of benzene in gas, liquid, and solid phases, with special emphasis on the experimental advances obtained by spectroscopic techniques in the past few years. Throughout, the symbolism used is that shown in the following reaction scheme:

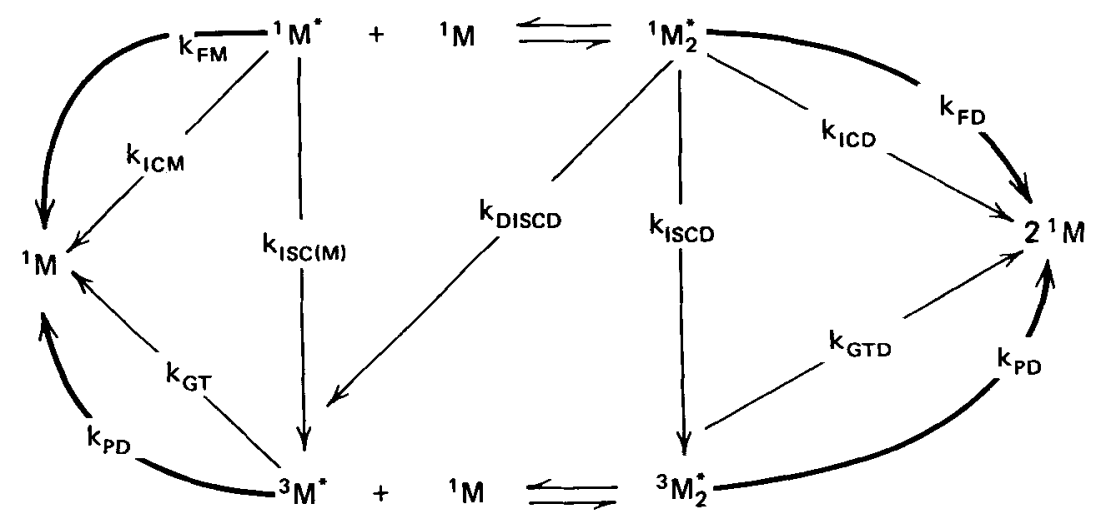

\section{THE NATURE OF THE LOWER EXCITED STATES OF BENZENE}

The near-ultraviolet spectral characteristics, and photophysical decay processes of benzene are generally described in terms of transitions between the various $\pi$ molecular orbitals formed by linear combination of the carbon $2 p$ atomic orbitals which have symmetries $b_{2 g}, e_{2 g}$ (two), $e_{1 g}$ (two), and $a_{2 u}$ within the 
$\mathrm{D}_{6 \mathrm{~h}}$ point group. Though the absolute energies and energy spacings of the orbitals are not known precisely, and are, to a degree, dependent upon the complexity of the calculatory method, the symmetries and ordering of energies generated by the simpler theories remain valid.

The ground state benzene configuration is $\left(a_{2 u}\right)^{2},\left(e_{1} g\right)^{4}$. Singly excited configurations are produced by promotion of an electron from one of the two degenerate $e_{1 g}$ orbitals to one of the degenerate $e_{2 y}$ orbitals (1). The predicted degeneracy of the states so produced $\left(B_{2 u}, B_{1 u}, E_{1 u}\right)$ is removed by electron interaction. Calculations (2) have shown that the ordering by energy of the trapsitions in which spin conservation is observed should be ${ }^{E_{1 u}}>1_{B_{1 u}}>{ }^{1} B_{2 u}$.

Experimental observations in the gas phase (3), solution (4), low-temperature glasses (5), rare gas matrices (6), and the crystal phase (7) have all confirmed that the lowest excited singlet state has symmetry, $B_{2 y}$, and that a transition from the ground to this state occurs around $260 \mathrm{~nm}$. Band intensity is very low ( $\varepsilon$ at $\lambda(\max ) \sim 250(8))^{*}$ as befits a symmetry forbidden, but vibrationally induced transition. Two more intense bands are observed on the high energy side of this ${ }^{1} B_{2 u}+A_{1 g}$ absorption; a medium-intensity band $(\varepsilon \sim 9000(8))$ around $205 \mathrm{gm}$ and a highintensity band $(\varepsilon \sim 70,000(8))$ around $190 \mathrm{~nm}$.

The $205 \mathrm{~nm}$ band is widely believed to be the ${ }^{1_{B_{1 u}}}+{ }^{1_{A}}{ }_{1 \mathrm{~g}}$ transition though some controversy is still attached to this assignment. Several recent semi-empirical (9-11), and ab initio (11) calculations place an $E_{2 g}$ state, arising from a doubly excited $\pi-\pi^{* *}$ transition below ${ }^{2} B_{1 u}$ state arising from a single $\pi-\pi^{*}$ excitation; supporting an early assignment (13) of the 205 $\mathrm{nm}$ band to a ${ }_{\mathrm{E}_{2}}{ }^{-1_{\mathrm{A}}} \mathrm{A}_{1 \mathrm{~g}}$ transition. A doubly excited configuration may be of comparable energy to a singly excited configuration due to the sensitivity of the energy of the $E_{2}$ configuration to electron interaction. Contrary evidence comes from another ab initio calculation (14) which places the ${ }^{1} \mathrm{E}_{2 g}$ state between the ${ }^{I_{E_{1 u}}}$ and ${ }^{1_{B_{1 u}} \pi-\pi^{*}}$ states. Still other calculations, semi-empirical (15) and ab initio (16) have placed the elusive ${ }_{E_{2 g}}$ state above ${ }^{1} E_{1 u}$. $\frac{1}{I t}$ is clear from this confusing situation that even the most sophisticated computations presently available, incorporating multiple excited configurations and multicenter corrections, are unsatisfactory in assigning even relative energies to the doubly excited $\pi-\pi^{* *}$ states. This is apparently due to the extreme sensitivity of $E_{2 g}$ state energies to the values chosen for the resonance integrals $(17)$.

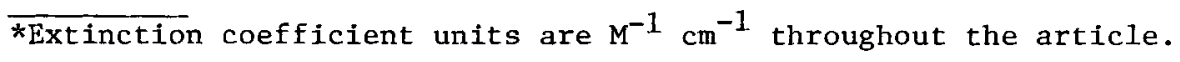


The common assignment of the $205 \mathrm{~nm}$ band to the ${ }^{1_{B}}{ }_{1 \mathrm{u}}+{ }^{1} \mathrm{~A}$ transition is consistent with the expected ordering of $1 \mathrm{u}$
state energies for those configurations arising from $e_{2 \mathrm{u}}+\mathrm{e}_{1 \mathrm{~g}}$ excitation, and with the assigned position of $1_{\mathrm{B}_{2 u}}$. Despite early inconclusive reports (18), recent evidence from vibrational analyses of low temperature absorption data in rare gas matrices and films (19) and of reflection spectra (20) confirms the ${ }^{1_{B_{1}}}$ assignment. However, electron impact spectra (21) under high resolution suggests that two electronic transitions occur in the $205 \mathrm{~nm}$ region; and this has been confirmed recently by absorption studies on benzene in perfluoro-n-hexane (22) and rare gas matrices $(22,23)$, at low temperature. In these environments the shift in the ${ }^{1} \mathrm{E}_{2 \mathrm{~g}}+{ }^{1} \mathrm{~A}_{1 \mathrm{~g}}$ transition is greater than that of the $\mathrm{I}_{\mathrm{B}_{1 \mathrm{u}}} \leftarrow \mathrm{I}_{\mathrm{A}} \mathrm{g}$ transition due to differences in the charge distribution of the configurations and allows separate observation of the two bands. Available experimental evidence favors the energy sequence deduced by Koutecky et a1. (9):

$$
{ }^{1_{E_{2 g}}^{+}}>{ }^{1} E_{1 u}^{+}>{ }^{1} B_{1 u}^{+}>1_{E_{2 g}^{-}}^{-}>{ }^{1} B_{2 u}^{-}>{ }^{1} A_{1 g}
$$

The high-intensity band $(\varepsilon \sim 70,000)$ around $190 \mathrm{~nm}$ is usually assigned to the ${ }^{1_{E_{1 u}}}{ }^{1_{A}}{ }_{1 g}$ symmetry-allowed $\pi-\pi^{*}$ transition, though some contribution to the intensity may come from the superposition of the first member of one of the Rydberg series. The $\pi-\pi^{*}$ assignment has been confirmed (24) from a vibrational analysis of the low-temperature spectrum of benzene in a rare gas matrix. Recent studies using multiphoton ionization spectroscopy have been considered to provide some indications of a ${ }^{1} \mathrm{E}_{1 \mathrm{~g}}$ state as an alternative to assignments for the elusive ${ }_{E_{2}}$ state (25). This conclusion awaits confirmation or otherwise by further experiments.

The relevant energies associated with each state are, to varying extents affected by the molecular environment, as discussed later. Table 1 contains approximate Franck-Condon maxima for the transitions from the ${ }^{1} \mathrm{~A}_{1 \mathrm{~g}}$ state.

In addition to transitions in the $\pi$ manifold discussed above, some attention has been given recently to possible $\sigma-\pi^{*}$ states in the ultraviolet nonradiative transitions from the ${ }^{1_{B}}{ }_{2}$ state. Callomon et a1. (27) have postulated the transitions from higher vibrational levels of ${ }^{B_{2 u}}$ to a ${ }^{3} E_{2 u}\left(\sigma-\pi^{*}\right)$ state to explain the onset of diffuseness in the high resolution absorption spectrum of vapor phase benzene in the $5.0 \mathrm{eV}$ region. Ab initio $(12,28)$ calculations have predicted the presence of at least one $\sigma$ state $\left(\mathrm{e}_{2} \mathrm{~g}\right.$ ) lying between two filled $\pi$-molecular orbitals. Photoionization $(29,30)$ experiments, and other evidence (31) appear to agree with the conclusion that $a \cdot \sigma-\pi^{*}$ transition may be 
TABLE 1. Approximate Franck-Condon maxima for transitions from $1_{\mathrm{A} g}$ ground state to the lower lying m-electronic states

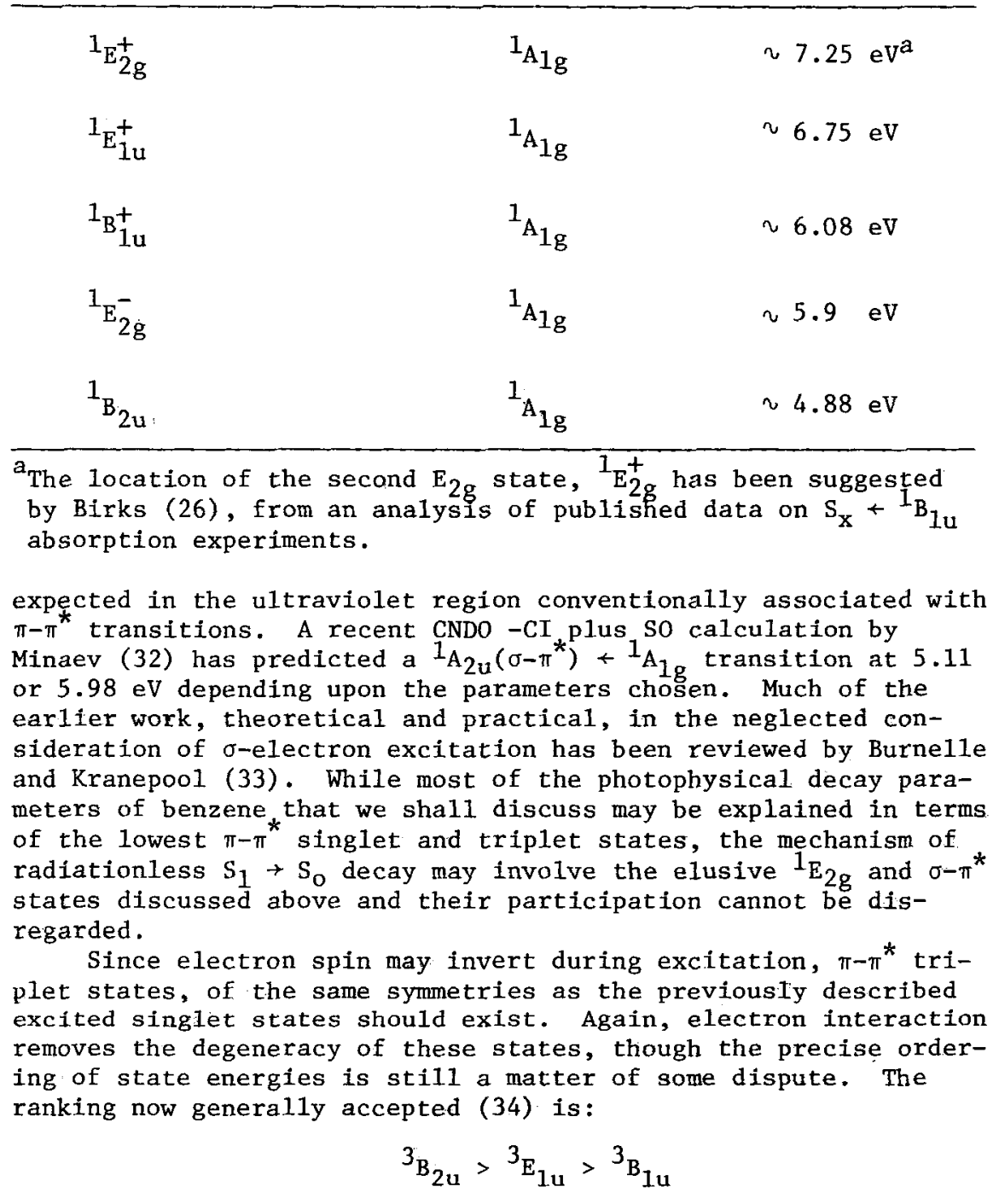

a sequence for which there is considerable experimental and theoretical justification (35). 
There is no interference in the lower $\pi-\pi{ }^{*}$ manifold from the ${ }^{3} \mathrm{E}_{2 \mathrm{~g}}$ states; both recent calculatory $(12,16,17,36)$ and experimental (37) evidence place the lowest energy ${ }^{3} \vec{E}_{2 g}$ configuration above the ${ }^{3} \mathrm{~B}_{2 u}$ state. Again, the relevant energies of the various states are dependent, to a degree, on the molecular environment, and in this case are more difficult to determine experimentally because of the multiplicity as well as symmetry forbidden nature of transitions from the ground state.

The selective data on Franck-Condon maxima for transitions from ${ }^{A_{1 g}}$, recorded in Table 2 , were obtained from electron impact ( 38 ) and $\mathrm{T}_{\mathrm{X}}+{ }^{3} \mathrm{~B}_{1 \mathrm{u}}$ transient absorption studies (39). They are considered at this stage to illustrate the relative positions of the triplet states vis-à-vis the singlet states discussed earlier.

TABLE 2. Approximate Franck-Condon maxima for transitions from $f_{A_{1}}$ ground state to the lower lying triplet $\pi-e l e c t r o n i c ~ e x c i t e d$ states.a
${ }^{3} E_{2 g}$
${ }^{1} A_{1 g}$
$\sim 6.55 \mathrm{eV}$
${ }^{3} \mathrm{~B}_{2 \mathrm{u}}$
${ }^{1} \mathrm{~A}_{1 \mathrm{~g}}$
$\sim 5.60 \mathrm{eV}$
${ }^{3} E_{1 u}$
${ }^{1_{A}}$
$\sim 4.75 \mathrm{eV}$
${ }^{3} \mathrm{~B}_{1 \mathrm{u}}$
${ }^{1} \mathrm{~A}_{1 \mathrm{~g}}$
$\sim 3.95 \mathrm{eV}$

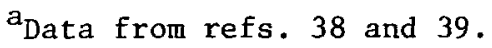

No information is available concerning $\sigma-\pi^{*}$ transitions, though from the approximate singlet assignments and presuming validity of Hund's Rule a $\sigma-\pi^{*}$ state or states may be expected to be within the energies of the lower $\pi-\pi^{*}$ manifold. It is interesting to speculate that the radiationless $\mathrm{T}_{1} \rightarrow \mathrm{S}_{0}$ decay, explained with such difficulty in theoretical analyses of the benzene problem, may involve a transition to a previously unconsidered ${ }^{3}\left(\sigma-\pi^{*}\right)$ state.

\section{TRANSITION BETWEEN THE LOWER ENERGY STATES}

Interstate transitions are generally considered to be governed principally by the familiar symmetry and multiplicity 
selection rules. The manner in which these rules affect the major excitation and decay routes of benzene are discussed below.

\section{A. Excitation from the ${ }^{1} \mathrm{~A}_{1 \mathrm{~g}}$ State}

Within the singlet manifold of the lower energy transitions only the $1_{E_{1 u}} * 1_{A_{1 g}}$ excitation is symmetry allowed, though transition to any of the ${ }^{1_{B_{1 u}}}, 1_{E_{2 g}}$, and $1_{\mathrm{B}_{2 u}}$ states can be promoted by coupling of the "pure" electronic states with vibrations of symmetry $\left(b_{2 g}, e_{2 g}\right),\left(e_{2 u}, b_{1 u}, b_{2 u}, e_{1 u}\right)$, and $\left(e_{2 g}, b_{1 g}\right)$, respectively. As mentioned above, all four transitions may be observed under certain circumstances, although ${ }^{\mathrm{E}_{1 \mathrm{u}}}+{ }_{\mathrm{A}_{1 \mathrm{~g}}} \mathrm{is}$, as expected, the most intense. The selection rules for double photon excitation predict that the modes of $b_{1 u}, b_{2 u}, e_{2 u}$ and $e_{1 u}$ symmetry should induce the absorption (40). Studies carried out by Hochstrasser, Sung, and Wesse1 (41) on a single crystal of benzene at $2^{\circ} \mathrm{K}$ show that a certain number of vibrations of $b_{1 u}, b_{2 u}, e_{1 u}$, and $e_{2 u}$ symmetry can be assigned in the two photon absorption spectrum. Gas phase two photon absorption spectra for benzene were reported recently by Wunsch, Neusser, and Schlag (42), who have found that the most powerful mode is of $b_{2 u}$ symmetry which is the extremely weak the $\nu_{19}$ mode of $\mathbf{e}_{1 \mathrm{u}}$ symmetry. Definitive experiments on the excited states of benzene using this promising technique are awaited.

For excitation into the triplet manifold, the transition ${ }^{3} E_{1 u} \leftarrow{ }^{1} A_{1 g}$ has first-order spin-orbit allowedness, while the ${ }^{3} \mathrm{~B}_{1 \mathrm{u}} \leftarrow \mathrm{1}_{\mathrm{A}} \mathrm{g}$ transition requires vibronic coupling via $\mathrm{e}_{2 \mathrm{~g}}, \mathrm{~b}_{1 \mathrm{~g}}$, or $\mathrm{D}_{2 \mathrm{~g}}$ modes or combination tones. Absorption studies (39) on oxygen free crystalline benzene have revealed a weak $\mathrm{T}_{2}+\mathrm{S}_{0}$ transition, but no $\mathrm{T}_{1}+\mathrm{S}_{0}$ transition, confirming the relative allowedness of the two transitions. Furthermore, an enhancement of the $\mathrm{T}_{1} \leftarrow \mathrm{S}_{0}$ absorption induced by high pressures of oxygen was recently reported for benzene and for a large number of simple benzene derivatives (43).

No experimental evidence is available for the ${ }^{3} \mathrm{~B}_{2 \mathrm{u}} \leftarrow \mathrm{I}_{\mathrm{A}_{1 \mathrm{~g}}}$ transition which is both spin and symmetry forbidden in the first order, and should occur in the same spectral region as the mediumintensit.y ${ }^{1} \mathrm{~B}_{1 \mathrm{u}}+{ }^{1_{\mathrm{A}}}{ }_{1 \mathrm{~g}}$ transition.

\section{B. Emission to the ${ }^{1} \mathrm{~A}_{1 \mathrm{~g}}$ State}

Kasha's Rule (44) requires that emission should occur from the lowest ${ }^{1} B_{2 u}$ and ${ }^{3} B_{1 u}$ states in benzene. This is essentially the case though a predictable very weak emission has been reported recently from higher states of oxygen-quenched benzene in gaseous (45) and solution (46) phases. The major fluorescence 
and phosphorescence processes for benzene are thus forbidden, and the radiative decay probabilities may be influenced by the environment as will be discussed below.

\section{Transitions Between Excited Singlet and Triplet States}

Intersystem crossing from the ${ }^{1_{B}}{ }_{2 u}$ envelope of vibronic states is thought to occur from the lowest vibrational leve1, or perhaps the lowest two or three such levels. Given the lower relative energies of ${ }^{3} \mathrm{E}_{1 \mathrm{u}}$ and ${ }^{3} \mathrm{~B}_{1 \mathrm{u}}$ states, transitions to each of these configurations from ${ }^{B_{2 u}}$, are possible, There is firstorder spin-orbit allowedness in that to the ${ }^{3_{\mathrm{B}}} \mathrm{lu}_{\mathrm{u}}$ state, but vibronic coupling is required for the transition to ${ }^{3} \mathrm{E}_{1 \mathrm{u}}$. Experimental evidence for intersystem crossing from higher electronic states is lacking, but there is no reason to neglect this route in the consideration of the decay processes of benzene molecules that have been so excited.

\section{EXCITED STATE GEOMETRY}

The ground state of the benzene molecule is perfectly hexagonal and the molecular wave functions may be used as bases for irreducible representations of the $\mathrm{D}_{6 \mathrm{~h}}$ point group. Transitions between the molecular energy states are usually excited in terms of the symmetry restrictions of this point group. The forbidden nature of the lower energy electronic transition has led to considerable discussion about the geometry of the excited states involved, since even slight deviations from regularity lead to reduction in symmetry, and require consequent modification of the selection rules. Despite early indications (47) that the phosphorescence spectrum may be explained using regular hexagonal symmetry, and recent evidence $(48)$ the $\mathrm{D}_{6 \mathrm{~h}}$ symmetry is maintained for ${ }^{3} \mathrm{~B}_{1 \mathrm{u}}$ benzene in eyclohexane at $77^{\circ} \mathrm{K}$, there is much evidence to show that the molecule is distorted when in the ${ }^{3} B_{1 u}$ state. Thirty years ago, Lewis and Kasha (49) presented evidence for a molecular contraction along the 1-4 axis, from analysis of phosphorescence data. Further results from gas phase ${ }^{3} B_{1 \mathrm{u}} \leftarrow{ }^{1} \mathrm{~A}_{1 \mathrm{~g}}$ oxygen-perturbed absorption spectra (50) led to a $\mathrm{D}_{2 \mathrm{~h}}$ assignment of the upper state. van der Waals and co-workers (51-55) have shown by ESR studies that the vibronic coupling in the triplet manifold between ${ }^{3} \mathrm{~B}_{1 \mathrm{u}}$ and ${ }^{3} \mathrm{E}_{1 \mathrm{u}}$ via the $\mathrm{e}_{2 \mathrm{~g}}$ vibrational mode plays the dominant role for the phosphorescence process and that this leads to a non hexagonal phosphorescent state distorted to a quinoidal form. Gwait et al. (56), using phosphorescence microwave double resonance, have studied the zero field origin of the 
0,0 band of phosphorescence of benzene- $h_{6}$ in benzene- $d_{6}$ at $1.6^{\circ} \mathrm{K}$. The results obtained are consistent with $\mathrm{a}^{3} \mathrm{~B}$ lu assignment for a distorted $D_{2 h}$ benzene phosphorescent state and the lowest triplet of toluene is also shown to have an expanded quinoidally distorted ring by the calculations of Haaland and Nieman (57). Evidence for a $\mathrm{D}_{2 \mathrm{~h}}$ assignment of the lowest triplet state in solid phase was also provided by other authors $(58,59)$.

Due to the highily forbidden nature of the ${ }^{3} B_{1 \mathrm{u}}+{ }^{1_{A}} \mathrm{~A}_{1 \mathrm{~g}} \mathrm{ab}-$ sorption, observations are only possible in perturbed systems such as in the presence of oxygen or in solid matrices, and it has been suggested that the symmetry distortions that have been deduced may arise from the influence of the molecular environment, rather than a genuine geometric property of the isolated molecule. While this possibility cannot be overlooked, theoretical considerations support the view that the ${ }^{3} \mathrm{~B}_{1 \mathrm{u}}$ state is inherently distorted. Davaquet $(60)$ has shown that the vibrations that stabilize the free ${ }^{3} \mathrm{~B}_{1 \mathrm{u}}$ molecules are precisely those that would cause a slight distortion similar to that suggested for the solid phase triplet molecule. Fujimura, Yanaguchi, and Nakajima (61) have calculated the ${ }^{3} \mathrm{~B}_{1 \mathrm{u}}$ state to have quinoidal $\mathrm{D}_{2 \mathrm{~h}}$ symmetry in agreement with an earlier theoretical analysis (62). These authors predict that the $1_{B_{1 u}}$ state will also be distorted with antiquinoidal $\mathrm{D}_{2 \mathrm{~h}}$ symmetry, and maintain that the lowest excited singlet state $\mathrm{I}_{\mathrm{B}_{2 \mathrm{u}}}$ will retain $\mathrm{D}_{6 \mathrm{~h}}$ symmetry, albeit with a slightly enlarged ring. This is not in agreement with conclusions of Nieman and Tinti (58) who have interpreted experimental results on the absorption, fluorescence, and phosphorescence of several issotopic benzenes in terms of a distortion of both the ${ }^{1} \mathrm{~B}_{2 \mathrm{u}}$ and ${ }^{3} \mathrm{~B}_{1 \mathrm{u}}$ states.

It is worthy of note that the photochemical production of Dewar benzene from the $1_{\mathrm{B}_{1 \mathrm{u}}}$ state $(63)$ and from the ${ }^{3} \mathrm{~B}_{1 \mathrm{u}}(64,65)$ is consistent with the quinoidal deformations suggested for these states.

A distortion of the $1^{B_{2 u}}$ state of benzene to $D_{3 d}$ has also been proposed (66) to account for inconsistencies in the interpretation of the ultraviolet spectrum of pure crystalline benzene at low temperatures. Such distortions may be the result of the solid medium or, more probably, the spectral inconsistencies may be due to state splitting by the environment.

\section{THE INFLUENCE OF THE ENVIRONMENT ON THE ELECTRONIC STATES}

The influence of different environments on molecular states has been studied, theoretically and practically, from changes in the absorption spectra. Such effects as frequency shifts, peak width changes, and variation of oscillator strength for various 
transitions are measures of the relative effects of different environments on the state involved.

The first absorption band of benzene shifts slightly to the red ( $~ 200-300 \mathrm{~cm}^{-1}$ ) with the change between vapor phase and solution, and further shifts dependent upon the nature of the solvent occur. The extent of such red shifts may be related qualitatively to medium refractive index and dielectric constant. Several theoretical approaches to the problems of spectral shifts have been attempted (67), but in general these are more useful for polar molecules, and to allowed transitions where shifts are of greater magnitude. Suffice to say that in benzene there is no discontinuity in the trend of shifts with refractive index, through gas, liquid, and solid phases, other than indicating that the forces of interaction between this molecule and the environment are weak. The crystalline phase is exceptional, since the "strict" selection rules for transition are broken down by interaction with the crystal field, which leads to factor group splitting (68) and the appearance of four (69) components of the 0-0 band, al1 of which are shifted.

Much experimental evidence is available on the small solvent shifts which are measureable but, since little effect on the photophysical decay processes is expected, no review of this work will be attempted; the reader is referred to the work of Eastman and Rehfeld (70) who report data for benzene in the vapor phase and in 37 different solvents.

Changes in oscillator strength are expected since this is a function of the refractive index of the medium (71), though the effect is much smaller than theoretically expected in the case of benzene. To a first approximation the oscillator strength for the ${ }^{1_{B_{2}}}+1_{A_{1 g}}$ transition is independent of molecular environment $(70)$.

A typical environmental effect on $S_{1} \leftrightarrow S_{0}$ transitions concerns the vibrational structure of the spectra. Loss of structure in solution relative to vapor and solid phases is the result of specific solute-solvent interactions and as such, is dependent upon the dielectric properties of the solvent. Lawson, Hirayama, and Lipsky (72) have reported observations on the absorption and fluorescence spectra of benzene in vapor phase and various solvents. Their data are consistent with the trend of increased broadening of bands and loss of structure with solvent polarity. Perfluorinated solvents exert the least effect, the spectra retaining much of the fine structure of the vapor phase. Figure 1 shows the data of Lipsky and co-workers (72) for vapor phase benzene, and for solutions in hexane and perfluorohexane.

The influence of environmental perturbations on the degree of allowedness of the symmetry-forbidden $0-0$ band has been 

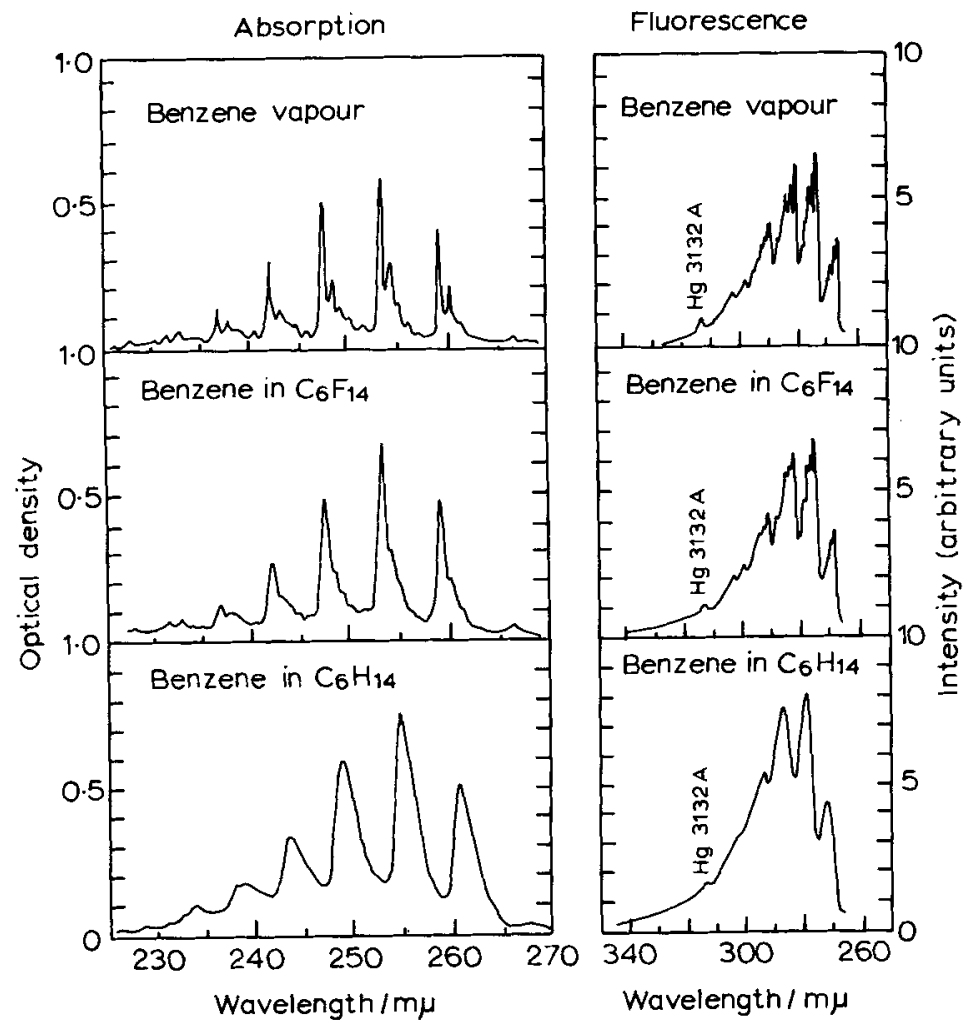

FIGURE 1. Absorption and emission spectra for benzene in (a) vapor phase, (b) perfluorohexane, (c) hexane. (Lawson et al. ${ }^{72}$ ).

thoroughly investigated. The first study on the effect was carried out by Ham (73) using benzene dissolved in hydrocarbon glasses with addition of carbon tetrachloride in various proportions. Bayliss and Hulme (74) also found a new absorption band appearing in benzene dissolved in carbon tetrachloride, chloroform and water, among other solvents, and a more detailed study was later carried out by Kanda (75) and by Bayliss and Cant (76). Platt (77) in a review concerned with the location of the second triplet state of benzene called these Ham bands and suggested that they arise from the spin forbidden ${ }^{3} \mathrm{E}_{1 \mathrm{u}} \leftarrow{ }^{1_{\mathrm{A}}}$ g transition, a view shared by other authors $(78,79)$. Robinson $(80)$ proposed 
that the Ham bands in carbon tetrachloride solid matrices are due to intensity borrowed from the solvent and have nothing to do with the ${ }^{3} \mathrm{E}_{1 \mathrm{u}}+{ }^{1_{\mathrm{A}}} \mathrm{I}_{1 \mathrm{~g}}$ transition. The correctness of this view was conclusively shown by Leach et al. (5), who have resolved the $0-0$ band of benzene fluorescence in presence of $\mathrm{CCl}_{4}$ at $77^{\circ} \mathrm{K}$, finding a mirror image of the $1_{\mathrm{B}_{2 \mathrm{u}}} \leftarrow \mathrm{1}_{\mathrm{A}_{1 \mathrm{~g}}}$ absorption including the Ham bands. Further absorption studies on Ham bands have been reported by other authors (82-86) and evidence for environmental enhancement of the $0-0$ bands of fluorescence and phorphorescence is also available (87-90).

A detailed investigation of the solvent effects on the intensity of the $0-0$ bands of $\mathrm{C}_{6} \mathrm{H}_{6}$ and $\mathrm{C}_{6} \mathrm{D}_{6}$ was recently carried out by Cundall and Pereira (91-93) by measuring fully corrected fluorescence and phosphorescence spectra, fluorescence and phosphorescence lifetimes, triplet yields, and electronic absorption spectra at various temperatures in a large variety of solvents. It was found that the rate constants for fluorescence and intersystem crossing are only slightly affected by solvent while the rate constant for the nonradiative process from $S_{1}$ to $S_{o}$ is solvent dependent, in agreement with results obtained ${ }^{1}$ by Eastman and Rehfeld (70). A good correlation was established between $k_{\mathrm{ICM}}$ and the extent of solvent-induced $0-0$ band intensity in both absorption and fluorescence bands (91). A solvent dependence on the rate constant $k_{I C M}$ was also found by Luria, Ofran, and Stein (94), who have measured fluorescence lifetimes of benzene in a series of polar and nonpolar solvents and the trend obtained is in good agreement with results of Cundall and Pereira (91). A similar correlation between the solvents enhancing the fluorescence $0-0$ band and the efficiency of the internal conversion from ${ }^{1_{1}}{ }_{1 u}$ to $1_{B_{2 u}}$ was reported by Lawson et a1. (72). This shows that solvents which give a higher probability of the nonradiative transition from $S_{3}$ to $s_{1}$ also increase the nonradiative transition from $S_{1}$ to $S_{0}$. In Fig. 2 the fully corrected fluorescence spectrum of benzene solutions in methanol at $77^{\circ} \mathrm{K}$ and the absorption spectrum at $233^{\circ} \mathrm{K}$ are represented (91); a good mirror relationship is displayed, including $0-0$ bands enhanced bands by solvent perturbation. It was also established by these authors that in the presence of chloroform and carbon tetrachloride the symmetry-forbidden $0-0$ bands are enhanced in both fluorescence and phosphorescence, while xenon enhances these bands only in phosphorescence. These effects are 11lustrated at $77^{\circ} \mathrm{K}$ in Figs. 3 and 4 , respectively, for benzene-d 6 in methylcyclohexane + chloroform and for benzene- $\mathrm{h}_{6}$ in ethanol and in ethanol + xenon. The extent of enhancement was given for fluorescence by the ratio $F_{0} / F_{1}$ in which Fo represents the peak 


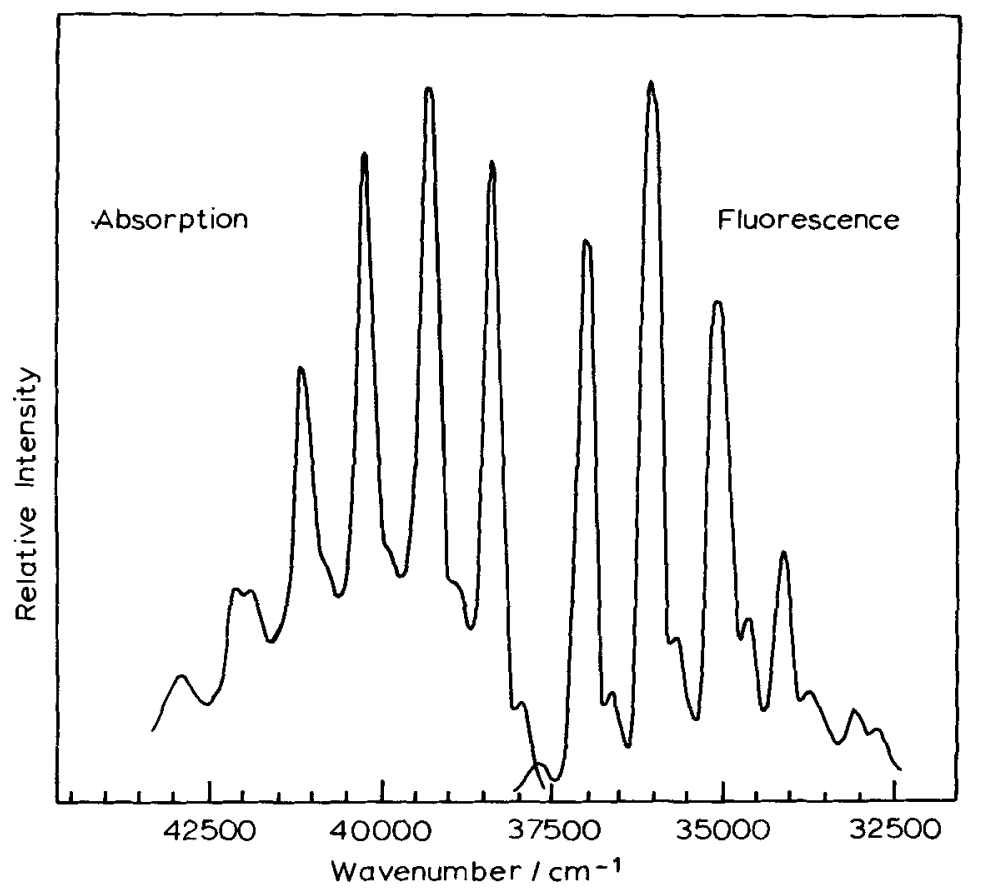

FIGURE 2. Absorption and fully corrected fluorescence spectra of benzene at $233^{\circ} \mathrm{K}$ and $770 \mathrm{~K}$, respectively. 92

height of the $0-0$ band and $F_{1}$ the peak height of the vibronic allowed band at the wavenumber $\bar{v}_{0-0}-606 \mathrm{~cm}^{-1}$, and for phosphorescence by the ratio $\mathrm{Po} / \mathrm{P}_{2}$, where $\mathrm{Po}$ is the peak height of the $0-0$ band and $P_{2}$ the corresponding peak intensity at about $\bar{v}_{0-0}-1500$ $\mathrm{cm}^{-1}$, as shown in Fig. 4. Some of the results obtained from this type of measurement are indicated in Tables 3 and 4 . From phosphorescence lifetimes, $\left(\tau_{p}\right)$, it was shown by the above authors that a decrease of $\tau_{p}$ and increase of the ratio of phosphorescence to fluorescence yield, $(\chi)$, parallels the enhancement of the $0-0$ phosphorescence band in most of the solvents investigated. The results were interpreted in terms of a distortion of both the ${ }^{1} B_{2 u}$ and ${ }^{3} B_{1 u}$ states induced by solvent perturbation, distortion in the ${ }^{3}{ }_{B} 1 \mathrm{u}$ state being greater than in the ${ }^{1_{B}}{ }_{2 u}$ state, in agreement with results reported by Nieman and Tinti (58). 


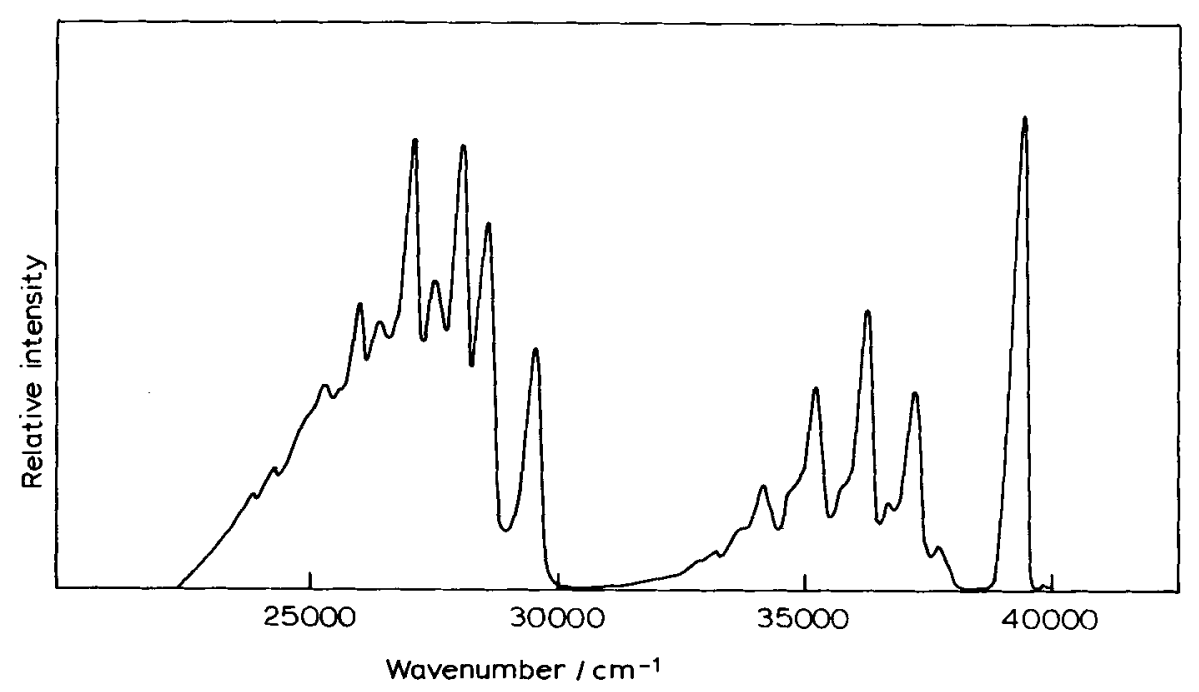

FIGURE 3. Futly corrected spectra (fluorescence and phosphorescence) of benzene in methylcyclohexane $+10 \%$ chloroform at $77^{\circ} \mathrm{K}, 92$ firstexcitation band.

Observations on transitions between $S_{0}$ and the lowest triplet state are difficult in nonrigid media and it is not possible to say with certainty that this transition is similarly affected by environment.

Nonradiative processes may occur other than through $\pi-\pi^{*}$ configurations. Other types of state may, as a result of their charge distributions, be more susceptible to interaction with the environment than the emitting $\pi, \pi^{*}$ states. 


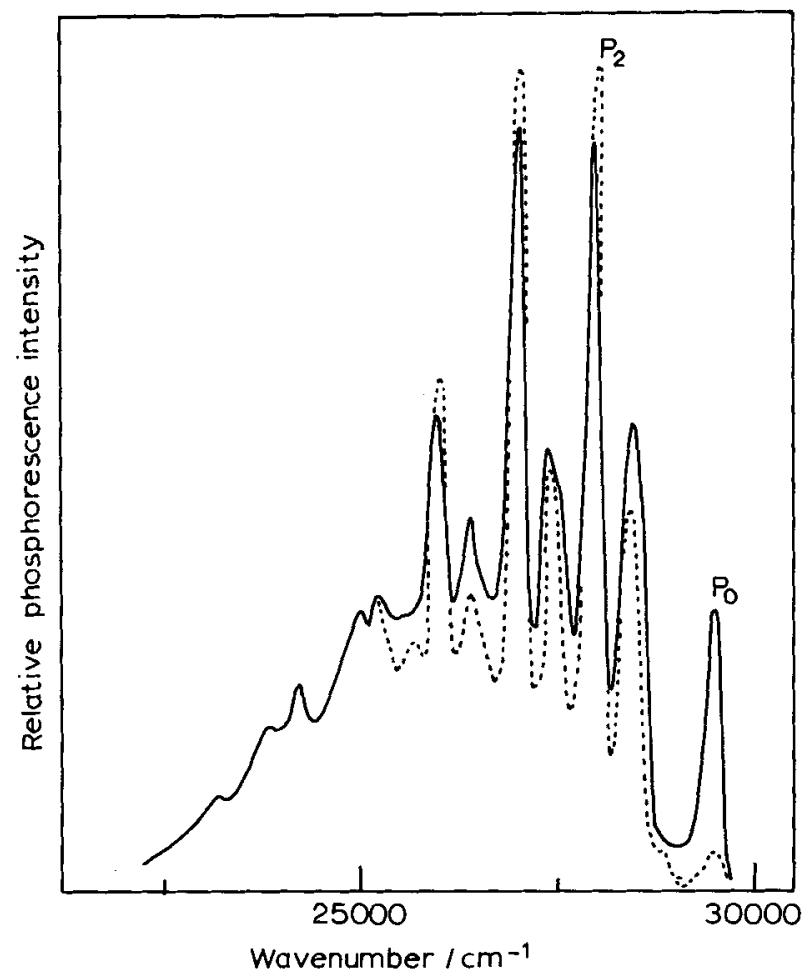

FIGURE 4. Fully corrected phosphorescence spectra of benzene in ethanol $\left(-\overline{-}^{--}\right)$and in ethano1 + xenon (—) at $77^{\circ} \mathrm{K} .92$

\section{THE $S_{1} \leftrightarrow S_{0}$ RADIATIVE TRANSITION}

The ${ }^{1_{B_{2 u}}} \leftarrow{ }^{1} A_{1 g}$ absorption transition has been we11 studied and is discussed in the previous sections. Theory predicts an integrated absorption intensity independent of temperature. Below room temperature, Eastman and Rehfeld (70) found a similar absorption spectrum for benzene in 2-methyl-1-propanol at $25^{\circ} \mathrm{C}$ and at $-140^{\circ} \mathrm{C}$, that at low temperature being sharper and better resolved. Above room temperature there is a rather more marked effect on peak intensity (95) accompanied by peak broadening and the expected increase in hot band intensity at $260 \mathrm{~nm}$. This is 
TABLE 3. Intensity of forbidden bands (fluorescence and phosphorescence) for benzene- $h_{6}$ in various solvents at $77^{\circ} \mathrm{K}$ (91-93).

\begin{tabular}{lcc}
\multicolumn{1}{c}{ Solvent } & $\mathrm{F}_{0} / \mathrm{F}_{1}$ & $\mathrm{P}_{0} / \mathrm{P}_{2}$ \\
\hline Methylcyclohexane & 0.050 & 0.074 \\
Methylcyclohexane $+10 \% \mathrm{CHCl}_{3}$ & 0.155 & 0.530 \\
Methylcyclohexane $+7 \% \mathrm{C} \mathrm{Cl}_{4}$ & 0.094 & 0.280 \\
Ethanol & 0.076 & 0.070 \\
Methano1 & 0.077 & 0.060 \\
Acetonitrile & 0.110 & - \\
Ethanol + xenon ( $0.8 \mathrm{M})$ & - & 0.380 \\
\hline
\end{tabular}

TABLE 4. Intensity of forbidden bands (fluorescence and phosphorescence) for benzene- $d_{6}$ in various solvents at $770 \mathrm{~K}$ (97-93).

\begin{tabular}{lcc}
\multicolumn{1}{c}{ Solvent } & $\mathrm{F}_{0} / \mathrm{F}_{1}$ & $\mathrm{P}_{0} / \mathrm{P} 2$ \\
\hline Methylcyclohexane & 0.072 & 0.040 \\
Methylcyclohexane $+10 \% \mathrm{CHC}_{3}$ & 0.234 & 0.470 \\
Methylcyclohexane $+20 \% \mathrm{CHCl}_{3}$ & 0.260 & 0.440 \\
Methylcyclohexane $+10 \% \mathrm{CCl}_{4}$ & 0.146 & 0.260 \\
Ethanol & 0.082 & 0.047 \\
Methanol & 0.076 & 0.060 \\
Acetonitrile & 0.100 & - \\
Ethanol + xenon $(20.8 \mathrm{H})$ & - & 0.26 \\
\hline
\end{tabular}


well illustrated in Figs. 5 and 6 . The changes are brought about by variations in energy distribution within the system, and the integrated intensity is approximately constant $(70,94)$. At very high temperatures the spectrum becomes very broad as observed in shock wave experiments (96).

The ${ }^{1_{B_{2 u}}} \leftarrow{ }^{1} A_{1 g}$ symmetry forbidden emission transition observed in all three phases, results from vibrational perturbation of the ground state. The fluorescence spectrum follows the changes in resolution, shape, and frequency with environment, observed in the absorption spectrum. It is, in all cases, a fair mirror image of the absorption spectrum, demonstrating that emission occurs from the electronic state created by absorption in the $260 \mathrm{~nm}$ region. Fluorescence intensity varies considerably with environment (see Tables 5 - 11), though as will be shown, this results from media effects on competitive processes, rather than on the probability of emission.

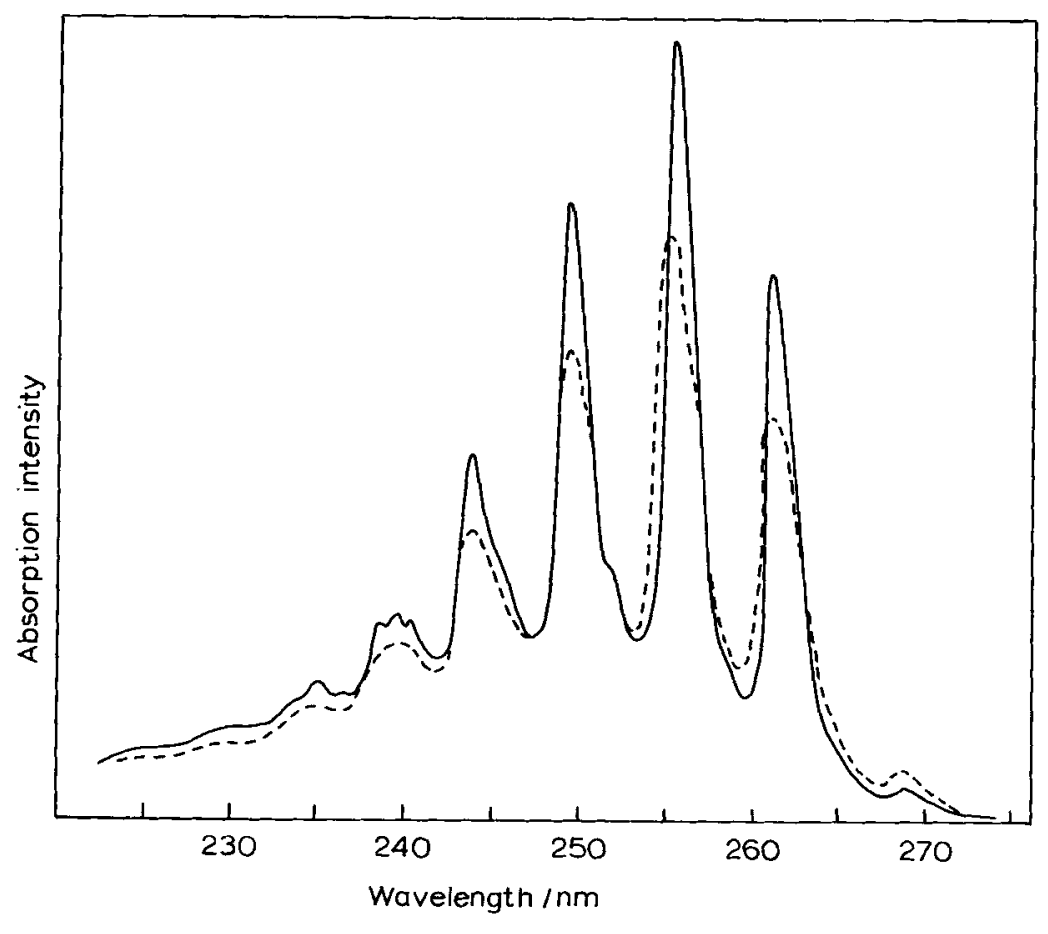

FIGURE 5. Variation in absorption spectrum (first band) with temperature for benzene in cyclohexane, $11^{\circ} \mathrm{C}(\ldots) 75^{\circ} \mathrm{C}(\ldots)$ ( $\ldots$ (... 


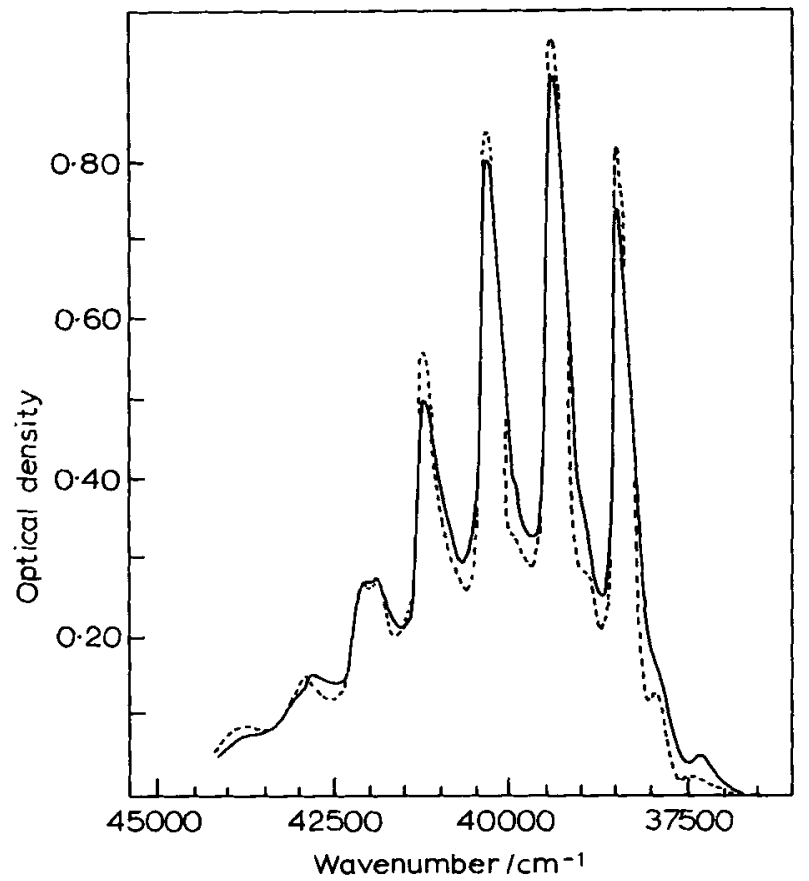

FIGURE 6. Absorption spectra of benzene in methanol at grom temperature (_) and at $\left.-40^{\circ} \mathrm{C}(-\cdots)\right)^{92}$.

One of the most significant advances in spectroscopic techniques in recent years has given data on single vibronic level fluorescence yields and associated emission lifetimes of individual vibronic levels. Details of the experimental technique and of the results achieved have been reviewed by Parmenter (97). Parmenter and Schuyler $(98,99)$ succeeded in recording fluorescence spectra from low pressure $(<0.2$ torr) benzene vapor excited with a band pass sufficiently small $\left(\sim 40 \mathrm{~cm}^{-1}\right)$ to ensure that single vibrational levels of the ${ }^{1} B_{2 u}$ state were created. In the lower levels the spectra recorded were sharp and structured, as would be expected in a system in which collisional redistribution of energy prior to fluorescence does not occur. At higher energy excitation the emission spectra become more diffuse, and the fluorescence intensity drops to zero when levels of excess energy 
TABLE 5. Monomer fluorescence yields in the gas phase.

\begin{tabular}{|c|c|c|c|c|}
\hline$\emptyset \mathrm{F}$ & Isomer & Temp. $\left({ }^{\circ} \mathrm{C}\right)$ & Conditions/Remarks & Ref. \\
\hline 0.21 & $\mathrm{C}_{6} \mathrm{H}_{6}$ & 30 & 2 torrs, $254 \mathrm{~nm}$ excitation & $(100)$ \\
\hline 0.32 & $\mathrm{C}_{6} \mathrm{H}_{6}$ & 30 & $0.077-0.12$ torr $\lambda_{\text {exc }} 254 \mathrm{~nm}$ & $(101)$ \\
\hline 0.39 & $\mathrm{C}_{6} \mathrm{H}_{6}$ & 30 & $0.01-0.4$ torr $\lambda_{\text {exc }} 254 \mathrm{~nm}$ & $(102)$ \\
\hline 0.22 & $\mathrm{C}_{6} \mathrm{H}_{6}$ & & For zeroth leve1 & $(98)$ \\
\hline 0.27 & $\mathrm{C}_{6} \mathrm{H}_{6}$ & & $\begin{array}{l}\text { For } 1 \text { st } e_{2} \text { band low-pressure } \\
\text { vapor }\end{array}$ & ( 98$)$ \\
\hline 0.18 & $\mathrm{C}_{6} \mathrm{H}_{6}$ & & & (103) \\
\hline 0.39 & $\mathrm{C}_{6} \mathrm{H}_{6}$ & & $\mathrm{P} \geq 10^{-2}$ torr $\lambda_{\text {exc }} 254 \mathrm{~nm}$ & (104) \\
\hline 0.18 & $\mathrm{C}_{6} \mathrm{H}_{6}$ & 25 & $\mathrm{P}>10$ torrs $\lambda_{\text {exc }} 254 \mathrm{~nm}$ & $(105)$ \\
\hline 0.31 & $\mathrm{C}_{6} \mathrm{H}_{6}$ & 30 & P $\quad 10-32$ torrs $\lambda_{\text {exc }} 264 \mathrm{~nm}$ & $(100)$ \\
\hline 0.23 & $\mathrm{C}_{6} \mathrm{D}_{6}$ & 25 & P 10 torrs $\lambda_{\text {exc }} 254 \mathrm{~nm}$ & $(105)$ \\
\hline 0.53 & $\mathrm{C}_{6} \mathrm{D}_{6}$ & 30 & P 4-15 torrs $\lambda_{\text {exc }} 264 \mathrm{~nm}$ & $(100)$ \\
\hline 0.26 & $\mathrm{C}_{6} \mathrm{D}_{6}$ & 30 & P $\quad 5.2$ torrs $\lambda_{\operatorname{exc}} 254 \mathrm{~nm}$ & $(100)$ \\
\hline 0.35 & $\mathrm{C}_{6} \mathrm{D}_{6}$ & & $\begin{array}{l}\text { Low-pressure-single leve } 1 \\
\text { fluorescence, zeroth leve } 1\end{array}$ & $(106)$ \\
\hline
\end{tabular}

$>2500 \mathrm{~cm}^{-1}$ are excited. Quantum yields for the emission from the various levels were estimated from the established high pressure yield of 0.18. Data are given in Tables 5 and 6 .

Further quantum yield measurements (111) and emission lifetimes $(111-113,115)$ have also been reported which demonstrate that the radiative transition probability from a vibronic state is determined by the combination of vibrational modes that have been excited. The transition rates that may be of interest in comparing data from al1 three phases are, of course, those from the lower levels of $\mathrm{s}_{1}$, since relaxation in higher-pressure gases and condensed media will lead to these states. The data of Spears and Rice (111) show that the emission probability from the levels $0,6^{1} 16^{1}$ and $1^{1}$ are $2.2 \times 10^{6} \mathrm{~s}^{-1}, 3.4 \times 10^{6} \mathrm{~s}^{-1}$, 
TABLE 6. Monomer fluorescence lifetimes in the gas phase.

\begin{tabular}{|c|c|c|c|}
\hline${ }^{\tau} \mathrm{F} / \mathrm{ns}$ & Isomer & Conditions & Ref. \\
\hline 60 & $\mathrm{C}_{6} \mathrm{H}_{6}$ & High pressure $(5-40 \mathrm{~mm}) \lambda_{\text {exc }} 230-280 \mathrm{~nm}$ & $(107)$ \\
\hline 80 & $\mathrm{C}_{6} \mathrm{H}_{6}$ & High pressure $\lambda_{\text {exc }} 259 \mathrm{~nm}$ & $(108)$ \\
\hline 77 & $\mathrm{C}_{6} \mathrm{H}_{6}$ & $\lambda_{\text {exc }} 260$, extrapolated to zero pressure & $(109)$ \\
\hline $80 \pm 10$ & $\mathrm{C}_{6} \mathrm{H}_{6}$ & $3-10$ torrs, $\lambda_{\text {exc }} 254 \mathrm{~nm}$ & $(110)$ \\
\hline 100 & $\mathrm{C}_{6} \mathrm{G}_{6}$ & -Zeroth level / low pressure & (111) \\
\hline 79 & $\mathrm{C}_{6} \mathrm{H}_{6}$ & 1st $e_{2}$ leve1 & \\
\hline 90 & $\mathrm{C}_{6} \mathrm{H}_{6}$ & -Zeroth leve1 low pressure & (112) \\
\hline 80 & $\mathrm{C}_{6} \mathrm{H}_{6}$ & $-1 s t e_{2}$ level & (112) \\
\hline 72 & $\mathrm{C}_{6} \mathrm{H}_{6}$ & High pressure $\lambda_{\text {exc }} 247-266 \mathrm{~nm}$ & (113) \\
\hline 164 & $\mathrm{C}_{6} \mathrm{D}_{6}$ & Zeroth level low pressure & (113) \\
\hline 125 & $\mathrm{C}_{6} \mathrm{D}_{6}$ & -1 st $e_{2}$ level & (113) \\
\hline 92 & $\mathrm{C}_{6} \mathrm{D}_{6}$ & High pressure limit $\lambda_{\text {exc }} 247-266$ & (113) \\
\hline 200 & $\mathrm{C}_{6} \mathrm{D}_{6}$ & Zeroth level & (113) \\
\hline 95 & $\mathrm{C}_{6} \mathrm{D}_{6}$ & High pressure $\left(5-40\right.$ torrs) $\lambda_{\text {exc }} 230-280$ & (106) \\
\hline 72 & $\mathrm{C}_{6} \mathrm{H}_{6}$ & 50 torrs indep. of $\lambda_{\text {exc }} 245-270 \mathrm{~nm}$ & (114) \\
\hline 92 & $\mathrm{C}_{6} \mathrm{D}_{6}$ & 50 torrs indep. of $\lambda_{\text {exc }} 245-270 \mathrm{~nm}$ & (114) \\
\hline
\end{tabular}

$3.4 \times 10^{6} \mathrm{~s}^{-1}$, and $2.5 \times 10^{6} \mathrm{~s}^{-1}$, respectively. Data from the comparable transitions $(106)$ in $C_{6} D_{6}$ give the values $1.75 \times 10^{6} \mathrm{~s}^{-1}$, $2.9 \times 10^{6} \mathrm{~s}^{-1}, 3.3 \times 10^{6} \mathrm{~s}^{-1}$, and $3.0 \times 10^{6} \mathrm{~s}^{-1}$, respectively. In benzene- $d_{6}$ the sharp drop in quantum yield with energy in excess of zero point level for the transition is noted (106) in a similar region to that for $\mathrm{C}_{6} \mathrm{H}_{6}$, about $3500 \mathrm{~cm}^{-1}$ above the $0-0$ band.

With increase in benzene (or added gas) pressure, the rate of collisional redistribution of excitation energy becomes 
TABLE 7. Rate constants for fluorescence of benzene- $h_{6}$ and benzene- $d_{6}$, as a function of temperature assuming a nonquenchable internal conversion process.

\begin{tabular}{|c|c|c|}
\hline & $\mathrm{T}\left({ }^{\circ} \mathrm{C}\right)$ & $k_{F} \times 10^{6}\left(s^{-1}\right)$ \\
\hline \multirow{7}{*}{ Benzene-h 6} & 25 & 2.76 \\
\hline & 40 & 2.79 \\
\hline & 50 & 2.84 \\
\hline & 60 & 2.93 \\
\hline & 70 & 3.06 \\
\hline & 80 & 3.24 \\
\hline & 100 & 3.72 \\
\hline \multirow{7}{*}{ Benzene-d 6} & 25 & 2.85 \\
\hline & 40 & 3.09 \\
\hline & 50 & 3.30 \\
\hline & 60 & 3.51 \\
\hline & 70 & 3.78 \\
\hline & 80 & 4.42 \\
\hline & 100 & 4.98 \\
\hline
\end{tabular}

competitive with the fluorescence rate to an extent which depends upon the total pressure of the system. Quantum yield and emission lifetime measurements reflect the nonequilibrium distribution of excited molecules in the medium-pressure range; for example, for excitation of $\mathrm{C}_{6} \mathrm{H}_{6}$ at $254 \mathrm{~nm}$, yields of (100) 0.21 (for $2 \mathrm{~mm}$ pressure) and a negative dependence upon increasing gas pressure have been reported. A similar dependence upon gas pressure is evident for $\mathrm{C}_{6} \mathrm{D}_{6}$; again for excitation at $254 \mathrm{~nm}$, yields of $0.33(100), 0.28(100), 0.26(100)$, and 0.23 (116) have been reported for pressures of $1.23 .0,5.2$, and $>10$ torrs, respectively. Also the work of Poole (100) has demonstrated that the yield is a function of excitation wavelength, dropping to zero in both benzene and the per-deutero derivative at excitation wavelengths of $240 \mathrm{~nm}$ and below. 
TABLE 8. Monomer fluorescence yields for benzene in solution.

\begin{tabular}{|c|c|c|c|c|c|}
\hline$\emptyset$ F̂M & Isomer & $\begin{array}{l}\text { Temp. } \\
\left({ }^{\circ} \mathrm{C}\right)\end{array}$ & Solvent & Remarks & Ref. \\
\hline 0.060 & $\mathrm{C}_{6} \mathrm{H}_{6}$ & 25 & Hexane & $\begin{array}{l}\text { Relative to } \\
\text { toluene }\end{array}$ & $(119)$ \\
\hline 0.052 & $\mathrm{C}_{6} \mathrm{H}_{6}$ & 25 & Me-cyclohexane & & (119) \\
\hline 0.061 & $\mathrm{C}_{6} \mathrm{H}_{6}$ & 25 & Cyclohexane & & $(70)$ \\
\hline 0.046 & $\mathrm{C}_{6} \mathrm{H}_{6}$ & 25 & Me-cyclohexane & & $(70)$ \\
\hline 0.058 & $\mathrm{C}_{6} \mathrm{H}_{6}$ & 25 & Hexane & & $0,120)$ \\
\hline 0.060 & $\mathrm{C}_{6} \mathrm{H}_{6}$ & 25 & Hexane & & $(121)$ \\
\hline 0.061 & $\mathrm{C}_{6} \mathrm{H}_{6}$ & 25 & Cyclohexane & & $(122)$ \\
\hline 0.053 & $\mathrm{C}_{6} \mathrm{H}_{6}$ & AMB & Hexane & & (123) \\
\hline 0.050 & $\mathrm{C}_{6} \mathrm{H}_{6}$ & 20 & Hexane & & $(124)$ \\
\hline 0.071 & $\mathrm{C}_{6} \mathrm{H}_{6}$ & 25 & Me-cyclohexane & $\begin{array}{l}\text { Relative to } \not \mathrm{F} M \\
\text { (DPA) }=1.0\end{array}$ & (125) \\
\hline 0.070 & $\mathrm{C}_{6} \mathrm{H}_{6}$ & RMT & Cyclohexane & & (126) \\
\hline 0.066 & $\mathrm{C}_{6} \mathrm{D}_{6}$ & 25 & Cyclohexane & & (126) \\
\hline 0.042 & $\mathrm{C}_{6} \mathrm{D}_{6}$ & 24 & Me-cyclohexane & & (127) \\
\hline 0.042 & $\mathrm{C}_{6} \mathrm{H}_{6}$ & RMT & Ethanol & & (128) \\
\hline 0.040 & $\mathrm{C}_{6} \mathrm{H}_{6}$ & 25 & Ethano1 & & (119) \\
\hline 0.025 & $\mathrm{C}_{6} \mathrm{H}_{6}$ & 25 & Acetonitrile & & (119) \\
\hline 0.029 & $\mathrm{C}_{6} \mathrm{H}_{6}$ & 25 & Methanol & & (119) \\
\hline 0.027 & $\mathrm{C}_{6} \mathrm{H}_{6}$ & 25 & Methanol & & $(70)$ \\
\hline 0.033 & $\mathrm{C}_{6} \mathrm{H}_{6}$ & 25 & Ethane & & $(70)$ \\
\hline 0.025 & $\mathrm{C}_{6} \mathrm{H}_{6}$ & 25 & Acetonitrile & & (119) \\
\hline 0.006 & $\mathrm{C}_{6} \mathrm{H}_{6}$ & 25 & Water & & $9,130)$ \\
\hline 0.0058 & $8 \mathrm{C}_{6} \mathrm{H}_{6}$ & 25 & Water & & $(70)$ \\
\hline 0.065 & $\mathrm{C}_{6} \mathrm{H}_{6}$ & 25 & Per-fluoro-n-hexane & & $(91)$ \\
\hline
\end{tabular}


TABLE 9. Monomer fluorescence emission lifetimes for benzene in solution.

\begin{tabular}{|c|c|c|c|c|}
\hline $\begin{array}{l}{ }^{\top} \text { FM } \\
\text { (ns) }\end{array}$ & Isomer & $\begin{array}{l}\text { Temp. } \\
\left({ }^{\circ} \mathrm{C}\right)\end{array}$ & Solvent & Ref. \\
\hline 29 & $\mathrm{C}_{6} \mathrm{H}_{6}$ & RMT & Cyclohexane & $(126)$ \\
\hline 24 & $\mathrm{C}_{6} \mathrm{H}_{6}$ & 20 & Hexane & (131) \\
\hline 26 & $\mathrm{C}_{6} \mathrm{H}_{6}$ & RMT & Cyclohexane & (132) \\
\hline 27.5 & $\mathrm{C}_{6} \mathrm{H}_{6}$ & 24 & Hexane & (133) \\
\hline 29.5 & $\mathrm{C}_{6} \mathrm{H}_{6}$ & 25 & Cyclohexane & (134) \\
\hline 32 & $\mathrm{C}_{6} \mathrm{H}_{6}$ & 20 & $\mathrm{n}$-Nonane & (135) \\
\hline 27.9 & $\mathrm{C}_{6} \mathrm{H}_{6}$ & 25 & Me-cyclohexane & (136) \\
\hline 45 & $\mathrm{C}_{6} \mathrm{H}_{6}$ & RMT & Hexane & (137) \\
\hline 34 & $\mathrm{C}_{6} \mathrm{H}_{6}$ & 25 & Cyclohexane & (119) \\
\hline 30 & $\mathrm{C}_{6} \mathrm{H}_{6}$ & 25 & Me-cyclohexane & (119) \\
\hline 33.6 & $\mathrm{C}_{6} \mathrm{H}_{6}$ & 25 & Hexane & (138) \\
\hline 26.6 & $\mathrm{C}_{6} \mathrm{D}_{6}$ & 25 & Cyclohexane & (125) \\
\hline 33 & $\mathrm{C}_{6} \mathrm{D}_{6}$ & 22 & Cyclohexane & (139) \\
\hline 28 & $\mathrm{C}_{6} \mathrm{H}_{6}$ & 25 & Cyclohexane & (139) \\
\hline 30 & $\mathrm{C}_{6} \mathrm{D}_{6}$ & 25 & Me-cyclohexane & $(127)$ \\
\hline 31 & $\mathrm{C}_{6} \mathrm{H}_{6}$ & RMT & Ethano1 & (121) \\
\hline 26 & $\mathrm{C}_{6} \mathrm{H}_{6}$ & 25 & Ethanol & $(119)$ \\
\hline 20 & $\mathrm{C}_{6} \mathrm{H}_{6}$ & 25 & Methane & (119) \\
\hline 2.2 & $\mathrm{C}_{6} \mathrm{H}_{6}$ & 25 & Water & (129) \\
\hline 15 & $\mathrm{C}_{6} \mathrm{H}_{6}$ & 25 & Acetonitrile & (119) \\
\hline
\end{tabular}


TABLE 10. Fluorescence yields for benzene in the solid phase.

\begin{tabular}{|c|c|c|c|c|c|}
\hline$\emptyset \mathrm{FM}$ & Isomer & $\begin{array}{l}\text { Temp. } \\
\left({ }^{\circ} \mathrm{K}\right)\end{array}$ & Solvent & Remarks & Ref. \\
\hline 0.21 & $\mathrm{C}_{6} \mathrm{H}_{6}$ & 77 & & & (148) \\
\hline 0.26 & $\mathrm{C}_{6} \mathrm{H}_{6}$ & 77 & EPA & $\pm 10 \%$ & (149) \\
\hline 0.20 & $\mathrm{C}_{6} \mathrm{H}_{6}$ & 77 & EPA & & $(150)$ \\
\hline 0.22 & $\mathrm{C}_{6} \mathrm{H}_{6}$ & 173 & Benzene & & (151) \\
\hline 0.29 & $\mathrm{C}_{6} \mathrm{H}_{6}$ & 77 & Crysta1 & & (152) \\
\hline 0.22 & $\mathrm{C}_{6} \mathrm{H}_{6}$ & 77 & EOA & $\begin{array}{l}\text { Ether/isooctane/ } \\
\text { alcohol }\end{array}$ & (144) \\
\hline 0.19 & $\mathrm{C}_{6} \mathrm{H}_{6}$ & 77 & EPA & & $(153-155)$ \\
\hline 0.27 & $\mathrm{C}_{6} \mathrm{D}_{6}$ & 77 & EPA & & (153-155) \\
\hline 0.21 & $\mathrm{C}_{6} \mathrm{H}_{6}$ & & n-Hexane & & (120) \\
\hline 0.18 & $\mathrm{C}_{6} \mathrm{H}_{6}$ & & Methano1 & & (120) \\
\hline 0.17 & $\mathrm{C}_{6} \mathrm{H}_{6}$ & 30 & $\begin{array}{l}30 / 70 \text { iso } \\
\text { but/isopent }\end{array}$ & $\begin{array}{l}\text { Limiting low- } \\
\text { temp. values }\end{array}$ & (120) \\
\hline 0.21 & $\mathrm{C}_{6} \mathrm{H}_{6}$ & & EPA & & (120) \\
\hline
\end{tabular}

TABLE 11. Fluorescence emission lifetimes for benzene in the solid phase.

\begin{tabular}{rcllc}
\hline $\begin{array}{c}\tau_{\mathrm{F}} \\
(\mathrm{ns})\end{array}$ & $\begin{array}{c}\text { Temp. } \\
\left({ }^{\mathrm{O}} \mathrm{K}\right)\end{array}$ & Solvent & Remarks & Ref. \\
\hline 84 & 173 & Benzene & $\begin{array}{l}\text { No phosphorescence } \\
\text { detected }\end{array}$ & $(151)$ \\
$120 \pm 6$ & 77 & Me-cyc1ohexane & $(93)$ \\
$115 \pm 5$ & 77 & Ethanol & $(93)$ \\
\hline
\end{tabular}


It is considered that pressures of 10 torr or greater are required for complete collisional deactivation to an equilibrium distribution of energy between levels prior to emission. Under these conditions, the fluorescence yield appears independent of further increases in pressure, and achieves a value of 0.18 $(100,103,105,116)$ for all first singlet band excitation wavelengths in excess of $247 \mathrm{~nm}$.

Fluorescence yields for $\mathrm{C}_{6} \mathrm{H}_{6}$ and $\mathrm{C}_{6} \mathrm{D}_{6}$ decrease $(100,105)$ with increasing temperature; the data of Dunnicliff (105) are presented in Fig. 7 for $2.5 \times 10^{-4} \mathrm{M}$ and $7.1 \times 10^{-4} \mathrm{M}$ benzene between 20 and $140^{\circ} \mathrm{C}$.

Emission lifetimes for benzene with vapor phase are subject to similar variations with pressure and excitation wavelength as are fluorescence yields. Data are collected in Table 6 and can be seen to show considerable variation with source and experimental technique. Recent measurements, using a single-proton counting technique (114) have shown the emission lifetimes of high pressure $\mathrm{C}_{6} \mathrm{H}_{6}$ and $\mathrm{C}_{6} \mathrm{D}_{6}$ to be 77 and $92 \mathrm{~ns}$, respectively, at $25^{\circ} \mathrm{C}$. The temperature dependence of the fluorescence lifetime is also shown in Fig. 7.

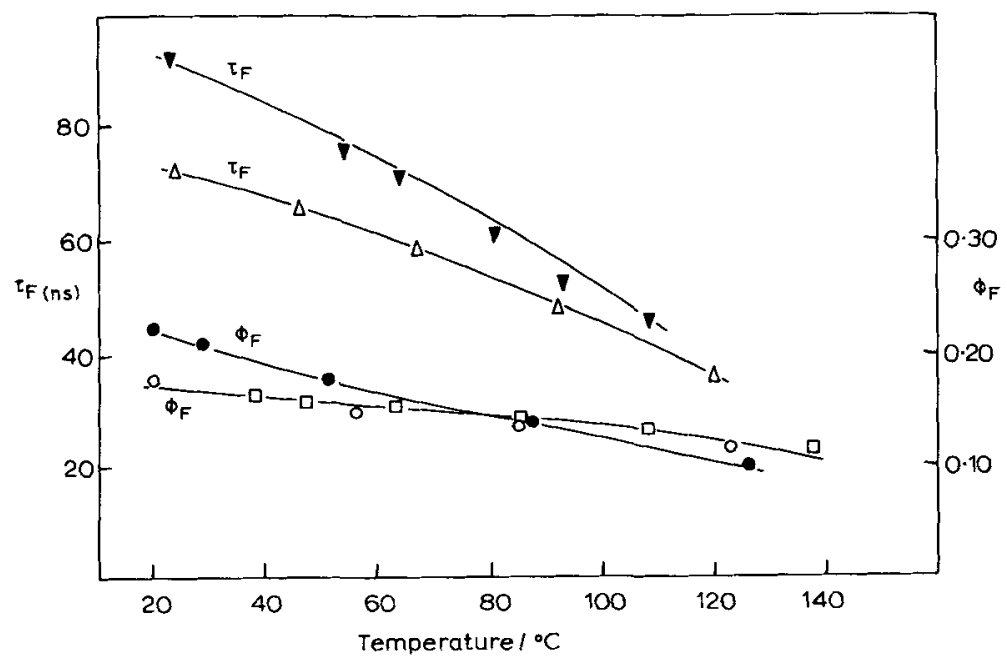

FIGURE 7. The variation in $\emptyset_{F}$ and $\tau F$ for vaporphase benzene as functions of temperature (Dunnicliff 105 and Lockwood 174 ). The filled points are for $\mathrm{C}_{6} \mathrm{D}_{6}$. The open points are for $\mathrm{C}_{6} \mathrm{H}_{6}$. 
At high pressures gaseous system most closely resemble the situation in condensed media, and it is instructive to determine the radiative rate constant for this system, and its variation with temperature. Assuming that internal conversion from $\mathrm{S}_{1}$ is a nonquenchable process which occurs prior to vibrational relaxation from a nonequilibrated state and using results of $\emptyset_{\mathrm{F}}$ and $\emptyset_{\mathrm{T}}$ determined by Cundall and Dunnicliff (105) and values of $\tau_{F}$ due to Lockwood (114), the calculated $\mathrm{k}_{\mathrm{F}}$ values are presented in Table 7 for both $\mathrm{C}_{6} \mathrm{H}_{6}$ and $\mathrm{C}_{6} \mathrm{D}_{6}$. The similarity of rate constants for the protonated and deuterated molecules indicates that the large differences in yield and lifetime for the two isomers are the result of an isotope effect on a nonradiative transition.

In the medium pressure region, it has been suggested that fluorescence in the collisionally equilibrated gas phase system results from two (117) or three (118) vibrational levels of $\mathrm{s}_{1}$. Whether this be the case, and if emission involves a multistep cascade through vibrational levels, it seems likely from considerations of the levels initially populated, the rates of vibrational deactivation, and the Boltzmann distribution of levels in the equilibrated system, that emission is dominated by transitions from the zeroth level. This is borne out by comparison of high-pressure values of $k_{F}$ with zeroth-leyel transition probability discussed previous1y; $2.8 \times 10^{-6} \mathrm{~s}^{-1}$ and $2.2 \times 10^{6} \mathrm{~s}^{-1}$, respectively, for $\mathrm{C}_{6} \mathrm{H}_{6}$ at $25^{\circ} \mathrm{C}$; though the discrepancy is greater for $\mathrm{C}_{6} \mathrm{D}_{6}$ for which the values are $2.9 \times 10^{6} \mathrm{~s}^{-1}$ and $1.7(5) \times 10^{6} \mathrm{~s}^{-1}$.

In solution, the quantum yields and lifetimes for fluorescence emission for benzene are dependent upon solvent (see Tables 8 and 9 , and more detailed data in reference 70) and temperature (140), but yield has been shown (141-145) to be independent of excitation wavelength within the first absorption band ( $\lambda$ exc > $230 \mathrm{~nm}$ ). The observed variations arising from different exciting sources and experimental methods, in yield and lifetime for similar and even identical solvents reflect the difficulty experienced in obtaining reliable fluorescence data. Despite this unfortunate limitation, some trends may be discerned. In general, quantum yields and lifetimes tend to be larger in nonpolar solvents (91, 119), although in all cases these quantities are much smaller than in the gas phase. There appears to be no significant isotope effect on either parameter, contrary to expectation from a comparison with gas phase data $(107,112)$.

The oscillator strength for the $\mathrm{S}_{1} \leftarrow \mathrm{S}_{0}$ transition is almost independent of solvent $(70,74,94)$, and it might thus be expected that the effect of solvent on the radiative probability would be slight. Cundall and Pereira $(91,119)$ have reported measurements of $\mathrm{k}_{\mathrm{FM}}$ in polar solvents, nonpolar solvents, and in particular perfluoro-n-hexane (in which solvent the similarity of 
spectral characteristics to those in vapor phase show that the solute-solvent interactions are minimal). It is found that although slight variations in $\mathrm{k}_{\mathrm{FM}}$ with solvent occur, the variations are not accounted for by considerations of solvent polarity, and it may well be that $\mathrm{k}_{\mathrm{FM}}$ is independent of solvent; lying within the range $1.5-1.8 \times 10^{6} s^{-1}$. The variation of $\emptyset_{F}$ and $\tau_{F}$ with solvent must, therefore, be the result of a medium effect on the nonradiative decay process. The difference between mean monomer transition probability in a range of solvents, and values from high-pressure and zeroth-level gas phase data is significant: $1.5-1.8 \times 10^{6} \mathrm{~s}^{-1}$ compared with $2.2 \times 10^{6} \mathrm{~s}^{-1}$ and $2.8 \times 10^{6} \mathrm{~s}^{-1}$. Application of the disputed refractive index, $\mathrm{n}^{2}$, correction further increases the divergence between these data; while the theoretical value for $k_{F M}\left(2.5 \times 10^{6} s^{-1}\right)$ derived using the StricklerBerg equation, neglecting $\mathrm{n}^{2}$ is in close agreement with the gas phase data. The phase effect may be the result of uncertainties in measurement of various parameters, or, more probably interactions in the condensed phase which are not explained by the $\mathrm{n}^{2}$ relationship. Reported data on $\mathrm{C}_{6} \mathrm{D}_{6}$ are less extensive than for $\mathrm{C}_{6} \mathrm{H}_{6}$ and contradictory. The data of Berlman (126) for $\emptyset_{\mathrm{F}}$ and $\tau_{\mathrm{F}}$ indicate that $\mathrm{k}_{\mathrm{F}}\left(\mathrm{C}_{6} \mathrm{D}_{6}\right)$ is larger than that for the perprotonated species. The data used by Sandros (146) and Helman (139) provide conclusions intermediate between those of Berlman (126), and those of Cunda11, olgivie, and Robinson (127), who reported a value for $\mathrm{k}_{\mathrm{F}}\left(\mathrm{C}_{6} \mathrm{D}_{6}\right)$ lower than that of $\mathrm{C}_{6} \mathrm{H}_{6}$. Rice and co-workers noted the similar trend in radiative lifetimes of the zeroth vibrational level in fluorescence $(106,111)$, and attributed the effect to a greater purity of the electronic levels in perdeuterobenzene, which is also mirrored by changes in oscillator strength with isotopic substitution ( 86 ).

It was noted earlier that there was a small temperature effect on $k_{F}$ in the gas phase. A similar effect is also observed in solution $(94,119)$. Although in nonpolar solvents the effect is relatively small $(119,136,147)$, it is accentuated in more polar environments (119). The effect is smaller for $\mathrm{C}_{6} \mathrm{D}_{6}$ :

Reliable fluorescence quantum yields and lifetimes in the solid phase are difficult to determine, and accurate data are sparse (see Tables 10 and 11 ). It is well established that fluorescence and lifetimes of dilute solutions of benzene increase with decreasing temperature $(8,119)$. In a recent study of similar molecules (156-158), it was shown that the increase in both $\emptyset_{F}$ and $\tau_{F}$ is smooth, and that both these quantities tend towards a limiting value at low temperature. An analysis of the temperature dependence of the two parameters for benzene in a variety of solvents (119) has indicated that the limiting values for both should be reached at a temperature well above $77^{\circ} \mathrm{K}$, since the controlling variable is the radiationless Channel III process(es) 
which has a solvent dependent activation energy characteristically in excess of $0.2 \mathrm{eV}$. The term "Channel III" has been introduced to describe the process or processes other than fluoresence or triplet state formation which lead to the disappearance of ${ }^{1} B_{2 u}$ state (see Section VIII). Measurements at $77^{\circ} \mathrm{K}$ are thought to provide the limiting low-temperature values for the two fluorescence parameters.

Eastman (120) has reported limiting yields of $0.21,0.18$, 0.17 , and 0.21 for benzene in $n$-hexane, methanol, $30 / 70$ isobutanol/ isopentane, and EPA, respectively. The yields are seen to be solvent dependent and determination of $k_{F}$ requires emission lifetimes in identical media. Such are not available though limiting values of 120 and 115 ns have found (93) for benzene in methylcyclohexane and ethanol, respectively, at $77^{\circ} \mathrm{K}$. Making the crude assumption that media effects are due to differences in solvent polarity we can calculate radiative rate constants of $1.75 \mathrm{x}$. $10^{6} \mathrm{~s}^{-1}$ for hydrocarbon solvents and $1.6 \times 10^{6} \mathrm{~s}^{-1}$ for alcohol solvents.

The similarity of these values to those mentioned earlier for room temperature solution work leads to the conclusions that the radiative rate constant is independent of temperature (below ambient) and that the difference between gas phase and condensed phase data is a real effect resulting from some molecular interaction not accounted for by the $\mathrm{n}^{2}$ correction which conventional theory requires.

\section{THE $S_{1} \rightarrow$ TRIPLET RADIATIONLESS TRANSITION}

From analysis of fluorescence yields and lifetime measurements on emission from single vibronic levels $(98,99,111-113,115)$ "rate constants" for total radiationless decay may be determined. These are also dependent upon vibrational level involved. Spears and Rice (111) have reported nonradiative lifetimes of 128, 108, 104, $105 \mathrm{~ns}$, respectively, for the levels considered previously. The fluorescence "cut off" region, noted in these reports, suggests, in agreement with several other indications discussed in Section VIII, that radiationless $S_{1} \rightarrow S_{0}$ decay proceeds via a highly vibrationally energetic level of $s_{1}$. The report of Rice and co-workers (106) on benzene-d 6 in this type of experiment shows that the nonradiative transition from $S_{1}$ is affected by deuteration to a greater extent than the fluorescence transition; the nonradiative lifetimes of the four comparable levels being $565,345,300$, and $340 \mathrm{~ns}$, respectively.

Triplet quantum yields for benzene vapor in collisionally deactivating systems have been estimated by a number of techniques (Table 12), involving sensitized isomeration, decomposition, or 
TABLE 12. The $S_{1}$ triplet transition for benzene in the gas phase.

\begin{tabular}{|c|c|c|c|c|c|c|}
\hline$\emptyset_{\mathrm{T}}$ & Isomer & $\begin{array}{l}\text { Temp } \\
\left({ }^{\circ} \mathrm{C}\right)\end{array}$ & & Conditions & Technique & Ref. \\
\hline 0.72 & $\mathrm{C}_{6} \mathrm{H}_{6}$ & Room & $2-19$ & torrs $\lambda_{\text {exc }} 254 \mathrm{~nm}$ & Butene-2 & (159) \\
\hline 0.72 & $\mathrm{C}_{6} \mathrm{H}_{6}$ & Room & $7-26$ & torrs $\lambda_{\mathrm{exc}} 252-67 \mathrm{~nm}$ & Butene-2 & $(160)$ \\
\hline 0.71 & $\mathrm{C}_{6} \mathrm{H}_{6}$ & Room & 10 to & 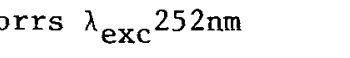 & Ketene & (161) \\
\hline 0.71 & $\mathrm{C}_{6} \mathrm{H}_{6}$ & Room & Cyclo & obutanone & $\begin{array}{l}\text { Cyclo- } \\
\text { butanone }\end{array}$ & $(162)$ \\
\hline 0.79 & $\mathrm{C}_{6} \mathrm{H}_{6}$ & Room & & & Pyrazine & (163) \\
\hline 0.63 & $\mathrm{C}_{6} \mathrm{D}_{6}$ & Room & $2-19$ & torrs $\lambda_{\mathrm{exc}^{254} \mathrm{~nm}}$ & Butene-2 & (159) \\
\hline 0.71 & $\mathrm{C}_{6} \mathrm{H}_{6}$ & Room & $>10$ & torrs $\lambda_{\mathrm{exc}}=254 \mathrm{~nm}$ & Butene-2 & $(105)$ \\
\hline 0.70 & $\mathrm{C}_{6} \mathrm{H}_{6}$ & 40 & $>10$ & torrs $\lambda_{\mathrm{exc}}=254 \mathrm{~nm}$ & Butene-2 & $(105)$ \\
\hline 0.68 & $\mathrm{C}_{6} \mathrm{H}_{6}$ & 60 & $>10$ & torrs $\lambda_{\mathrm{exc}}=254 \mathrm{~nm}$ & Butene-2 & $(105)$ \\
\hline 0.65 & $\mathrm{C}_{6} \mathrm{H}_{6}$ & 80 & $>10$ & torrs $\lambda_{\mathrm{exc}}=254 \mathrm{~nm}$ & Butene-2 & $(105)$ \\
\hline 0.63 & $\mathrm{C}_{6} \mathrm{H}_{6}$ & 100 & $>10$ & torrs $\lambda_{\mathrm{exc}}=254 \mathrm{~nm}$ & Butene-2 & (105) \\
\hline 0.61 & $\mathrm{C}_{6} \mathrm{D}_{6}$ & Room & $>10$ & torrs $\lambda_{\mathrm{exc}}=254 \mathrm{~nm}$ & Butene-2 & $(105)$ \\
\hline 0.52 & $\mathrm{C}_{6} \mathrm{D}_{6}$ & 50 & $>10$ & torrs $\lambda_{\mathrm{exc}}=254 \mathrm{~nm}$ & Butene-2 & $(105)$ \\
\hline 0.46 & $\mathrm{C}_{6} \mathrm{D}_{6}$ & 70 & $>10$ & torrs $\lambda_{\text {exc }}=254 \mathrm{~nm}$ & Butene-2 & $(105)$ \\
\hline 0.37 & $\mathrm{C}_{6} \mathrm{D}_{6}$ & 100 & $>10$ & torrs $\lambda_{\text {exc }}=254 \mathrm{~nm}$ & Butene-2 & $(105)$ \\
\hline
\end{tabular}

luminescence of additives. It is to be expected that the overall intersystem crossing efficiency is dependent upon the extent of collisional deactivation and redistribution of energy following excitation. The presence of appreciable quantities of added gas, which may arise because of the presence of the triplet monitor, and the use of benzene pressures in excess of 10 torrs ensure that the yields of triplets reported for gas phase systems result from intersystem crossing from thermally equilibrated range of levels in $S_{1}$. of the many triplet monitors used, it is widely believed that butene-2 effectively quenches only the triplet state. 
Dunnicliff (115) has shown that the olefin also quenches singlet $\mathrm{S}_{1}$ benzene, but only with a bimolecular rate constant of $2.2 \mathrm{x}$ ${ }_{10}^{1} 8 \mathrm{M}^{-1} \mathrm{~s}^{-1}$, so at the olefin concentrations commonly used for triplet scavenging, singlet state quenching is negligible compared with that of the triplet state.

Noyes and Harter (160) obtained evidence of a decrease in triplet yield with decrease of excitation wavelength. A limiting high-pressure yield of 0.71 at room temperature after excitation at $254 \mathrm{~nm}$ is now well established. The observed isotope effect is large; with corresponding high-pressure limit values of 0.63 (159) and 0.61 (105) reported for $\mathrm{C}_{6} \mathrm{D}_{6}$, under the same conditions. Using the emission lifetime measurements of Lockwood (114), intersystem crossing rate constants (for heavy and light benzene) of $7.9 \times 10^{6} \mathrm{~s}^{-1}$ and $11 \times 10^{6} \mathrm{~s}^{-1}$ are obtained assuming a nonquenchable internal conversion also occurs. For this transition, the crude assumption that the high-pressure rate constant is dominated by the contribution from the zeroth level may not be valid. As discussed earlier, transition may be to either or both of the ${ }^{3} \mathrm{E}_{1 \mathrm{u}}$ and ${ }^{3} \mathrm{~B}_{1 \mathrm{u}}$ states. Transition to ${ }^{3} \mathrm{~B}_{1 \mathrm{u}}$ has first-order spin-orbit allowedness, but the rate constant may be reduced by the small Franck-Condon overlap factor resulting from the $1.1 \mathrm{eV}$ energy gap between states. Transition to ${ }^{3} \mathrm{E}_{1 \mathrm{u}}$ requires vibronic coupling. The positions of the three states in $\mathrm{C}_{6} \mathrm{D}_{6}$ relative to the equivalent states in $\mathrm{C}_{6} \mathrm{H}_{6}$ are not accurately known, though spectroscopic evidence $(39,164,165)$ suggests that the energy spacings are slightly increased $\left(200 \mathrm{~cm}^{-1}\right)$ by deuteration. In addition, deuterium substitution reduces the energy separation of the vibrational levels (166-169). There is some confusion concerning whether deuterium atom substitution affects (170) the radiationless $\mathrm{T}_{1} \rightarrow \mathrm{S}_{\mathrm{o}}$ transition or otherwise. Because of this uncertainty, it is probably unacceptable to seek similarities between the measured rate constant in high-pressure gases and in the nonradiative decay rates of the zeroth vibrational levels of $\mathrm{s}_{1}$ states of $\mathrm{C}_{6} \mathrm{H}_{6}$ and $\mathrm{C}_{6} \mathrm{D}_{6}$.

Considerable data are available for triplet yields of ben-

zene in dilute solutions of different solvents (see Table 13). In the main, two techniques have been used; sensitized phosphorescence of biacetyl, sensitized cis-trans isomerization of butene2 , octene-2, and stilbene. All yield comparable results. In saturated hydrocarbon solvents at room temperature, the triplet yield for $\mathrm{C}_{6} \mathrm{H}_{6}$ is found to be about $0.24 \pm 0.01$. There is a so1vent dependence of this quantity, the yield dropping to 0.15 in ethanol, 0.13 in methano1, and 0.09 in acetonitrile (91). In determining the effect of environment on the rate constant controlling intersystem crossing, values for emission lifetimes in the various systems are needed. These are, as mentioned previously, of ten unreliable. Cunda11 and Pereira (91) have reported 
consistent data which give the variation in $\mathrm{k}_{\text {ISCM }}\left(=\emptyset_{\mathrm{T}} / \tau_{\mathrm{F}}\right)$ with solvent. It is found that, though differences between solvents occur, there is no consistent trend with solvent polarity, and we can consider $\mathrm{k}_{\mathrm{ISCM}}$ to be independent of solvent within the range of approximately $7( \pm 1) \times 10^{6} \mathrm{~s}^{-1}$. Further, there appears to be little isotopic effect on $k_{\text {ISCM }}$ since a rate constant of $8.7 \mathrm{x}$ $10^{6} \mathrm{~s}^{-1}$ has been reported for $\mathrm{C}_{6} \mathrm{D}_{6}(127)$ in methy1-cyclohexane at room temperature compared with $8.0 \times 10^{6} \mathrm{~s}^{-1}$ for the perprotonated solute (91).

The variation of $\mathrm{k}_{\text {ISCM }}$ with temperature for $\mathrm{C}_{6} \mathrm{H}_{6}$ in cyclohexane (182) is more marked than that for $\mathrm{C}_{6} \mathrm{D}_{6}$ (127) similar to the trends noted in gas phase studies (105). It is erronous to fit this temperature dependence to a simple Arrhenius function, since the yield of phosphorescence at low temperature shows a substantial triplet production in the solid phase. More realistically, the room temperature process may be viewed as the sum of two intersystem crossing steps to the two lowest triplet states. One process being temperature independent $\left({ }^{3} \mathrm{~B}_{1 \mathrm{u}}\right.$ ?) and the other temperature dependent $\left(\rightarrow^{3} E_{1 u}\right.$ ?).

Estimation of triplet yields from benzene in the solid phase presently requires several approximations, since the available triplet monitoring methods do not function in solid media. Pereira (93) has shown that the quantum deficit $1-\left(\phi_{F}+\phi_{\mathrm{T}}\right)$ may be assigned in benzene although not necessarily to substituted benzene derivatives, to a single process, and that $\left(\emptyset_{\mathrm{F}}+\emptyset_{\mathrm{T}}\right)$ approaches unity with decreasing temperature. In this way, the deficit $\left(1-\emptyset_{\mathrm{F}}\right)$ may be assigned to $\emptyset_{\mathrm{T}}$ at low temperatures. Using the emission yields and limiting low temperature lifetime data from Tables 10 and 11 , together with the solvent effect assumption noted previously, we may calculate rate constants of $6.6 \times 10^{6}$ and $7.1 \times 10^{6} \mathrm{~s}^{-1}$ for intersystem crossing in hydrocarbon and polar media, respectively.

It is seen that the rate constants for intersystem crossing are broadly, that is, within \pm 10 percent, independent of molecular environment. We must conclude that the significant differences noted in fluorescence and triplet yields and lifetimes, with phase, must be the result of an effect on the "hidden" $s_{1} \rightarrow s_{0}$ decay process.

\section{THE $S_{1} \rightarrow S_{0}$ RADIATIONLESS TRANSITION}

Evidence that decay of the first excited singlet state may occur via a nonradiative process which depends on the vibrational energy and probably does not involve the lower triplet states of the $\pi$ manifold comes from various types of experiment: 
TABLE 13. Triplet yields in the solution phase.

\begin{tabular}{|c|c|c|c|c|c|}
\hline$\emptyset_{\mathrm{T}}$ & Isomer & $\begin{array}{l}\text { Temp. } \\
\left({ }^{\circ} \mathrm{C}\right)\end{array}$ & Conditions & Monitor & Ref. \\
\hline 0.24 & $\mathrm{C}_{6} \mathrm{H}_{6}$ & 29 & Pure benzene & Piperylene & (172) \\
\hline 0.57 & $\mathrm{C}_{6} \mathrm{H}_{6}$ & 25 & Pure benzene & Butene-2 & (173) \\
\hline 0.60 & $\mathrm{C}_{6} \mathrm{H}_{6}$ & 25 & Pure benzene & Octene-2 & (174) \\
\hline 0.56 & $\mathrm{C}_{6} \mathrm{H}_{6}$ & 24 & Pure benzene & Butene-2 & $(175)$ \\
\hline 0.58 & $\mathrm{C}_{6} \mathrm{H}_{6}$ & 25 & Pure benzene & Stilbene & $(176)$ \\
\hline 0.71 & $\mathrm{C}_{6} \mathrm{H}_{6}$ & 25 & Pure benzene & Octene & (177) \\
\hline 0.24 & $\mathrm{C}_{6} \mathrm{H}_{6}$ & 24 & 0.11 2M cyclohexane & Butene-2 & (147) \\
\hline 0.25 & $\mathrm{C}_{6} \mathrm{H}_{6}$ & 26 & $6.10^{-2} \mathrm{M}$ Me-cyclohexane & Butene-2 & (178) \\
\hline 0.25 & $\mathrm{C}_{6} \mathrm{H}_{6}$ & 20 & Di1. cyclohexane & Biacetyl & $(146)$ \\
\hline 0.24 & $\mathrm{C}_{6} \mathrm{H}_{6}$ & 22 & Di1. Me-cyclohexane & Octene & $(177)$ \\
\hline 0.23 & $\mathrm{C}_{6} \mathrm{H}_{6}$ & 25 & Di1. cyclohexane & Butene-2 & ( 91) \\
\hline 0.24 & $\mathrm{C}_{6} \mathrm{H}_{6}$ & 25 & Dil. Me-cyclohexane & Butene-2 & $(91)$ \\
\hline 0.15 & $\mathrm{C}_{6} \mathrm{H}_{6}$ & 25 & Di1. ethano1 & Butene-2 & (91) \\
\hline 0.13 & $\mathrm{C}_{6} \mathrm{H}_{6}$ & 25 & Dil. methanol & Butene-2 & (91) \\
\hline 0.09 & $\mathrm{C}_{6} \mathrm{H}_{6}$ & 25 & Di1. acetonitrile & Butene-2 & $(91)$ \\
\hline 0.07 & $\mathrm{C}_{6} \mathrm{H}_{6}$ & 25 & Dil. water & Butene-2 & $(91)$ \\
\hline 0.47 & $\mathrm{C}_{6} \mathrm{H}_{6}$ & 24 & 0. IM cyclohexane & Butene-2 & $(175,178)$ \\
\hline 0.39 & $\mathrm{C}_{6} \mathrm{H}_{6}$ & 25 & $0.3 \mathrm{M}$ cyclohexane & $\begin{array}{l}\text { Flash } \\
\text { photolysis }\end{array}$ & $(179)$ \\
\hline 0.18 & $\mathrm{C}_{6} \mathrm{H}_{6}$ & 25 & Dil. cyclohexane & Stilbene & $(180)$ \\
\hline $\begin{array}{l}0.23 \\
(5)\end{array}$ & $\mathrm{C}_{6} \mathrm{D}_{6}$ & 25 & Dil. Me-cyclohexane & Butene-2 & $(178)$ \\
\hline 0.24 & $\mathrm{C}_{6} \mathrm{D}_{6}$ & 20 & Dil. cyclohexane & Biacetyl & $(181)$ \\
\hline 0.25 & $\mathrm{C}_{6} \mathrm{D}_{6}$ & 25 & Di1. cyclohexane & Butene-2. & $(127)$ \\
\hline 0.24 & $\mathrm{C}_{6} \mathrm{H}_{6}$ & 25 & Dil. perfluorohexane & Butene-2 & $(91)$ \\
\hline
\end{tabular}


1. The decrease in quantum yield for $S_{1} \rightarrow S_{0}$ fluorescence with increasing excitation energy has been reported for gas phase (142), 1iquid phase $(141,143,183)$, and solid phase (144) benzene systems. The decrease in yield shows that the onset of an additional competitive decay process, occurs at an energy above $S_{1}$ of the order of $0.3 \mathrm{eV}$.

2. Low-pressure, narrow band pass excitation studies have shown $(98,99,111-113)$ that the fluorescence yields from single excited vibrational levels of $S_{1}$ drop sharply to zero in region of $0.31 \mathrm{eV}$ above the zeroth level of the ${ }^{1} \mathrm{~B}_{2 \mathrm{u}}$ state. The effect is also noted in the perdeuterated molecule (106).

3. Callomon and co-workers (27) report the onset of spectral diffuseness in the $S_{0}-S_{1}$ absorption spectrum of benzene vapor at a level approximately $0.31 \mathrm{eV}$ above $\mathrm{S}_{1}$.

4. In the medium-pressure gaseous benzene system, Poole (100) has found that the $S_{1} \rightarrow S_{0}$ fluorescence yield drops to zero for excitation of wavelengths of $240 \mathrm{~nm}$ or less, despite efficient collisional deactivation.

Such triplet yields, as are available, show that the vibrationally enhanced process is not intersystem crossing.

A11 of these observations are consistent with the existence of a rapid nonradiative route available for the decay of excited benzene molecules with energy approximately $0.30 \mathrm{eV}$ above $\mathrm{s}_{1}$. The variation with temperature of the quantum deficit $\emptyset_{\mathrm{IC}}={ }^{\circ}$ $1-\left(\emptyset_{\mathrm{F}}+\emptyset_{\mathrm{T}}\right)$ has been analyzed kinetically in terms of a single process for benzene- $h_{6}(91,147)$ and benzene-d 6 (127) in solution. The assumption of a single decay process allows interpretation of the behavior with temperature of the rate constant $\mathrm{k}_{\mathrm{ICM}}\left(=\emptyset_{\mathrm{IC}} / \tau_{\mathrm{F}}\right)$ in terms of the Arrhenius equation which yields an activation energy which is solvent dependent (91), typically of the order of 0.25 to $0.37 \mathrm{eV}$, and is tentatively interpreted as the mean excess energy required by the thermally equilibrated excited benzene molecules, for decay via this hidden route.

There is also evidence (105) that the quantum deficit increases with temperature in the high-medium-pressure gaseous system. Analysis using the crude model applied to the solution phase data produces an "activation energy" for Channel III decay of $0.14 \mathrm{eV}$ for $\mathrm{C}_{6} \mathrm{H}_{6}$ and $0.19 \mathrm{eV}$ for $\mathrm{C}_{6} \mathrm{D}_{6}$. A kinetic scheme involving a nonquenchable radiationless decay of vibrationally excited $S_{1}$ states is thought (105) to provide a better fit for the data. Using this approach, the onset of nonradiative deactivation would occur at approximately $0.4 \mathrm{eV}$ above $\mathrm{S}_{1}$.

The experimental evidence proves, without question, the existence of a Channel III route; and various attempts have been made 
to provide some explanation. The theories of radiationless transitions applied with varying success to the $T_{1} \rightarrow S_{0}$ step (see section $X$ ) have not yet been able to explain satisfactorily the pure singlet decay phenomenon. It has been suggested that photochemical rearrangements could account for the quantum deficit. Evidence (184) (reviewed later in Section XII) has shown that the prismane and Dewar isomers would arise from states of $\mathrm{B}_{1 \mathrm{u}}$ symmetry, while benzvalene and fulvene result from the ${ }^{1} \mathrm{~B}_{2 \mathrm{u}}$ state. Bryce-Smith and Longuet-Higgins $(65,185)$ and Jano $(186)$ have suggested that diradical intermediates consistent with the symmetries of the $1_{\mathrm{B}_{2 u}}$ and ${ }^{3} \mathrm{~B}_{1 \mathrm{u}}$ states may be involved in the photoisomerization of benzene and its derivatives. Measured radical yields are very 1 ow (180), as are the final yields of isomeric products (187). Though rapid re-aromatization of the diradical, or of benzvalene has been proposed as an explanation of the low isomer yields, it is to be expected that isomerization due to group shifts should occur in the case of benzene derivatives. Examination of the photodecay processes in o-xylene (188) and $\mathrm{m}-\mathrm{xylene}$ (189) has shown that aromatic isomer products are formed in very small yields, and further, that the activation energy for production of $\mathrm{m}$-xylene from other isomers $(0.44 \mathrm{eV})$ is higher than the activation energy required for the temperature-dependent Channel III process $(0.21 \mathrm{eV})$. Birks (190), adopting the isomer theory of Lamola et a1. (191) and Noyes and co-workers (192), suggests a "physical" isomer, the most unusual property of which seems to be that, by definition, it is undetectable. It is suggested that the potential energy surfaces of this "isomer" overlap with those of $S_{0}$ and $S_{1}$ benzene, permitting rapid hidden decay. It is not clear how this differs from what would be conventionally regarded as internal conversion.

Callomon, Leach, and Lopez-Delgado (27) suggested that a $\sigma-\pi^{*}$ state existed in the region between the ${ }^{1_{B}}$ and ${ }^{1} B_{1 u}$ states (see Section II), and selected ${ }^{3} \mathrm{E}_{2 \mathbf{u}}$ as the most probable state involved. It has been suggested (156) that a singlet state would be more plausible in view of the very high rate constant for the transition from the ${ }^{1} \mathrm{~B}_{2 \mathrm{u}}$ state. The problem of decay of this newly invoked state remains since it is expected that the transition to ground state would be extremely forbidden, leading consequently to a long-lived intermediate. Recent photochemical data $(193,194)$ have shown the existence of a long-1ived, nonbenzvalene (194) intermediate following $2537 \mathrm{~A}^{\circ}$ irradiation of benzene. Results obtained by Stein $(94,195)$ in $\mathrm{O}_{2}$-free solutions of benzene have indicated the formation of benzvalene with an initial quantum yield of 0.18 after excitation with the $2537 \mathrm{~A}^{\mathrm{o}}$ line and that this initial yield is independent of temperature in the 9 to $50^{\circ} \mathrm{C}$ range. This result shows that isomer 
formation does not account for the thermally activated fluorescence quenching. Stein proposed that benzvalene arises from a higher vibronic state before vibrational relaxation to the $\mathrm{S}_{1}$ fluorescent state, that is, prior to interaction with the environment. Benzvalene is subsequently quenched by benzene triplet. Results of Lutz and Stein (195) also show an increase in the efficiency of benzvalene formation at higher temperatures, consistent with a decrease of $\emptyset_{\mathrm{T}}$, as determined by cundall and co-workers (196). Further results of Ilan and Stein (197) on the fluorescence yields of benzene solutions in the presence of xenon still support the assumption.

A recent tunneling effect model for radiationless transitions (198) has been applied to benzene and other aromatic hydrocarbons. The $\mathrm{CH}$ stretching vibrations are considered as dominant for the non-radiative process. Rate constants for the radiationless process $\mathrm{S}_{1} \rightarrow \mathrm{S}_{\mathrm{o}}$ calculated by theory are of the same order of magnitude as those obtained by experiment. A further possibility for the interpretation of Channel III is a delay via a configurationally perturbed doubly excited $E_{2 g}$ state, though this route seems unlikely following confirmation that the relevant state is of similar energy to ${ }^{1}{ }^{1}{ }_{1 U}$ (see Section II).

\section{THE $T_{1} \rightarrow S_{0}$ PHOSPHORESCENCE TRANSITION}

Considering the ease with which phosphorescence emission from solid or glassy phase solutions of benzene is observed, it is perhaps surprising that unambiguous data on the probabilities of radiative and radiationless decay of the triplet state are so difficult to obtain and unreliable. The determination of excited state parameters at a particular temperature requires, at least, evaluation of $\emptyset_{\mathrm{P}}, \phi_{\mathrm{T}}$ and $\tau_{\mathrm{P}}$, and more reliably $\emptyset_{\mathrm{P}}, \emptyset_{\mathrm{F}}$, $\emptyset_{\mathrm{T}}, \tau_{\mathrm{F}}$, and $\tau_{\mathrm{P}}$. Direct measurement of $\phi_{\mathrm{P}}$ by comparison of the emission of the given compound with that of a standard sample is one method of approach $(148,150)$. However, since it is necessary that both sample and standard possess identical optical properties (otherwise corrections for effects of refractive index differences, reflectivity losses, and emission polarization on the measurements must be made), this method is of limited applicability. Other methods for measuring $\emptyset_{\mathrm{P}}$ have been reported. Kellogg and Bennett (199) estimated phosphorescence yield from measurements of acceptor molecule fluorescence, resulting from triplet energy transfer from the aromatic donor molecule. This method should be reliable, provided solutions are sufficiently dilute to eliminate the effect of triplet-triplet annihilation and provided corrections for anisotropy of emission are made. 
A further method involves a comparison of the luminescence from a glassy sample with the light scattered by a MgO surface (149).

Because of the complexity and difficulty in obtaining reliable data, some authors $(8,200,201)$ have made the arbitrary assumption that $k_{P}=0.030 \mathrm{~s}^{-1}$ and is independent of temperature for all unsubstituted hydrocarbons. From this assumption, and measurements of $\tau_{P}$, values for $k_{G T}$ have been estimated. The subsequent theoretical analysis of the radiationless transition probability based on the assumption must, therefore, be treated with some caution, since it is arbitrary and probably incorrect.

A method for determining $k_{P}$ reported by Cundall and Pereira (91) utilizes data from the parallel studies on parameters controlling the spin-allowed emission. In these studies, most exhaustively pursued for benzene, it is found that both $k_{F}$ and $\mathrm{k}_{\text {ISC }}$ approach limiting low-temperature values, and estimates of their magnitude in the $<100^{\circ} \mathrm{K}$ region may be given with some certainty. With this information, the additional data for $\tau_{P}$ and for $\emptyset_{\mathrm{P}} / \emptyset_{\mathrm{F}}(\mathrm{x}), \mathrm{k}_{\mathrm{P}}$ can be determined, since

$$
\mathrm{k}_{\mathrm{P}}=\chi \mathrm{k}_{\mathrm{F}} / \mathrm{k}_{\mathrm{ISC}} \tau_{\mathrm{F}}
$$

This method does not rely upon any special assumptions, although corrections for photoselection effects (202-205) and for the eigenpolarization of the spectrophotometer must be undertaken. Further studies of fluorescence and phosphorescence at $77^{\circ} \mathrm{K}$ for simple benzene derivatives using the same spectrophotometer and the same optical arrangement carried out by Cundall and Ogilvie (158) have shown that photoselection and eigenpolarization corrections do not alter the results obtained for $k_{P}$ (within 2-3\%). The above method assumes reliable data for ${ }^{\top} P$ but measurements are subject to uncertainty. Variations in $\tau_{p}$ for a specific sample can be found which depend upon the rates of cooling of the sample, and also upon the time which elapses between the freezing process and the measurement operation. The cooling rate may affect the decay if two phases of the solid solvent can be formed (206-208). This is the case for cyclohexane matrices in which cubic matrices are produced by rapid freezing, and monoclinic matrices by slow freezing. Variations in $\tau_{p}$ with standing time can be observed if glass relaxation occurs (208210) and/or thermal equilibration is achieved only slowly (211). Though the effect of this latter factor may be reduced by using very narrow sample tubes, Martin and Kalantar (212) have shown that $\tau_{P}$ varies considerably with time elapsed following freezing, if the solvent utilized undergoes glass transitions in the neighborhood of the temperature used. For the particular case of benzene, $\tau_{P}$ is strongly dependent upon solvent and upon temperature above $60^{\circ} \mathrm{K}$. Solvent effects have been reported by 
Leubner (213), Hirayama (214), and Hatch et al. (215), among others (Fig. 8). In some instances, apparent solvent effects may be the result of impurity quenching, particularly in solvents of relatively low viscosity. However, this explanation cannot be universally valid and does not assist in understanding the unexpected temperature effect. Leubner (213) could find no correlation between sample viscosity and $\tau_{P}$, and Ling and Willard (216) reported, from measurements on 3-methyl pentane between 77 and $94^{\circ} \mathrm{K}$, that the viscosity had a pseudo-activation energy of 15.9 $\mathrm{kcal} / \mathrm{mol}$, a factor of 7 greater than the activation energy measured in much the same temperature range for $\tau_{P}$. A definitive examination of the problem has been published recently by Kilmer and Spangler (217) (Fig. 9). These authors found that the variation in $\tau_{P}$ for benzene in cyclohexane $\left(\sim 10^{-3} \mathrm{M}\right)$ with temperature could be fitted to the relationship of the type

$$
1\left|\tau_{P}=1\right| \tau_{0}+k_{1} \exp (-\Delta E \mid K T)
$$

For benzene-h 6 it was found that $\tau_{0}=11.44 \mathrm{~s} \Delta \mathrm{E} / \mathrm{hc}=554 \mathrm{~cm}^{-1}$ and $\mathrm{k}_{1}=4.2 \times 10^{3} \mathrm{~s}^{-1}$. The values for $\mathrm{C}_{6} \mathrm{D}_{6}$ are $14.28 \mathrm{~s}, 705 \mathrm{~cm}^{-1}$ and $218 \times 10^{3} \mathrm{~s}^{-1}, \tau_{P}$ is, of course, a composite function including radiative and nonradiative decay processes and there is still speculation concerning which mode of decay is temperature dependent and which not. The weight of evidence seems to favor the nonradiative route as being that which requires thermal activation. Use of the Kilmer-Spangler equation to extrapolate to room temperature produces phosphorescence lifetimes of 3.8 and $5 \mathrm{~ms}$ for $\mathrm{C}_{6} \mathrm{H}_{6}$ and $\mathrm{C}_{6} \mathrm{D}_{6}$, respectively. Since phosphorescence is not observed in either liquid or gas phases, it is clear that alternative decay routes operate in fluid media.

Some emission lifetime data are presented in Table 14. Particularly of note are the lifetimes in frozen inert gas solutions, reflecting the enhancement of $\mathrm{T}_{1} \rightarrow \mathrm{S}_{0}$ transition with increasing atomic number of the solvent; an effect also noted by other authors. The important results of Haaland and Nieman (222) show a marked solvent effect on phosphorescence lifetimes. Perfluorocarbons are the least perturbing solvents on phosphorescence, an effect consistent with results obtained in liquid solution $(72,91)$.

The effect of deuteration whose influence is independent of solvent and temperature, shows the importance of the importance of the $\mathrm{C}-\mathrm{H} / \mathrm{C}-\mathrm{D}$ modes in promoting one or both of the triplet decay transitions.

Using the values $\emptyset_{\mathrm{F}}=0.2^{120}, \chi\left(=\emptyset_{\mathrm{P}} / \emptyset_{\mathrm{F}}\right)=0.92(92,219)$ and $\tau_{P}=5.50 \mathrm{~s}$ for benzene in methyl cyclohexane, it is possible to calculate values of 0.0417 and $0.401 \mathrm{~s}^{-1}$ for $\mathrm{k}_{\mathrm{P}}$ and $\mathrm{k}_{\mathrm{GT}}$. The 


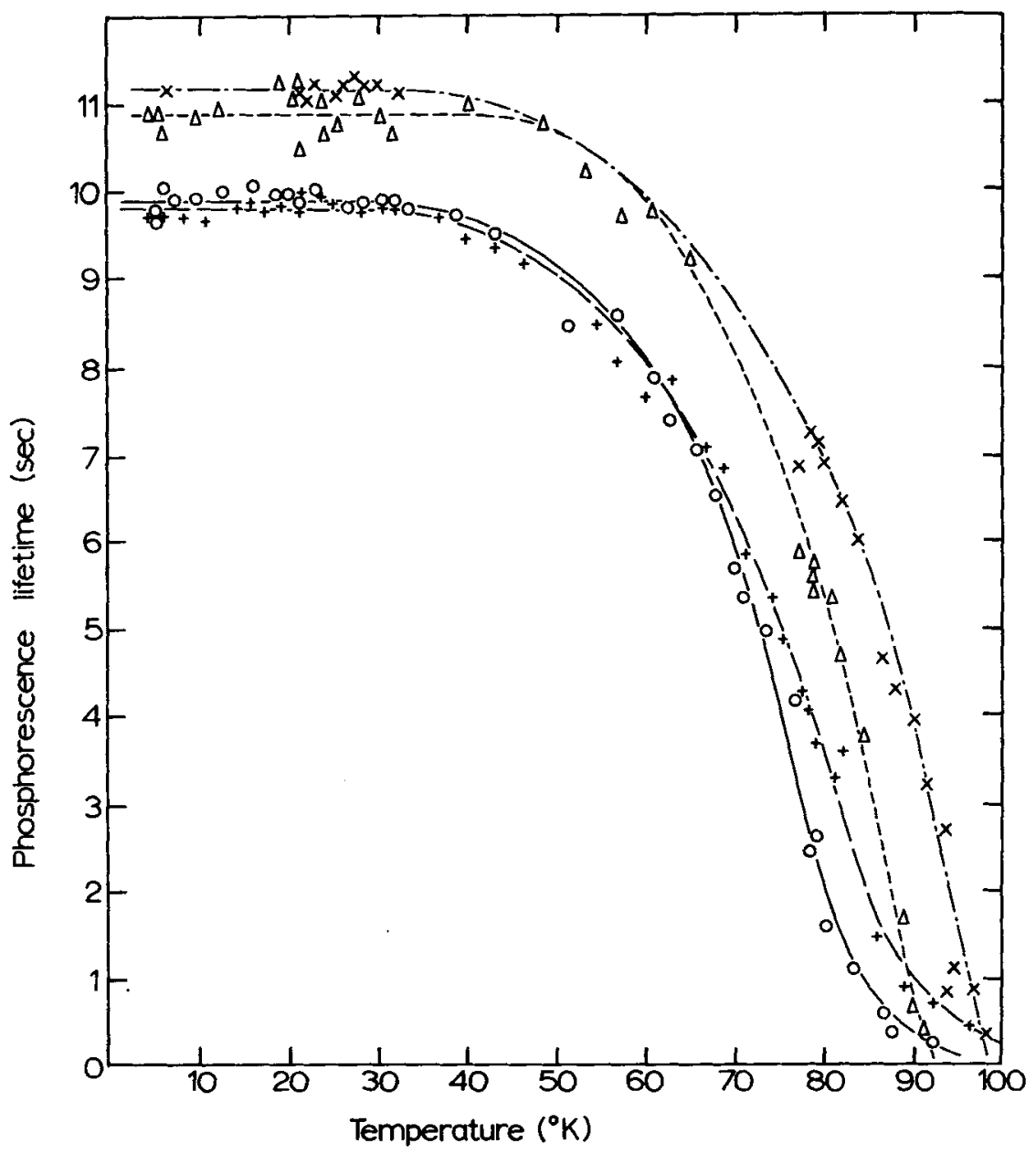

FIGURE 8. Temperature dependence of $\tau p$ for $\mathrm{C}_{6} \mathrm{H}_{6}$ in ethanol $(X)$, EPA $(\Delta), 3$-methylgentane $(0)$, and $\mathrm{MCH}-$ isopentane $(+)$, (Leubner). 213 


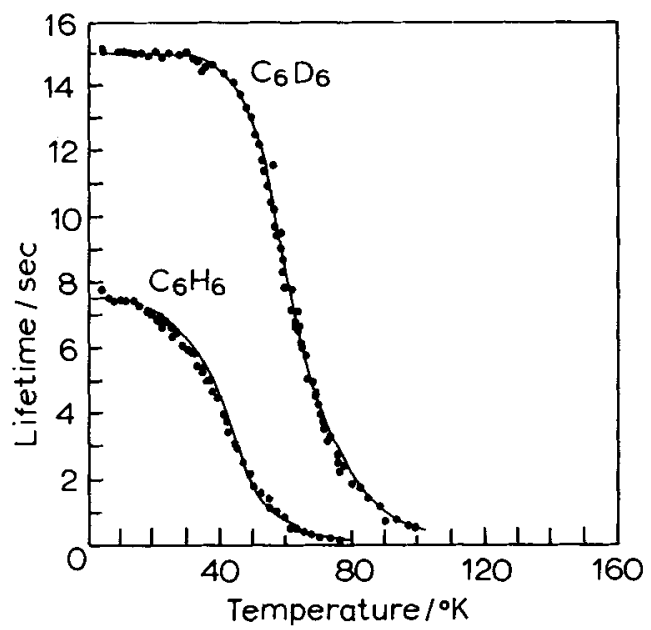

(b)

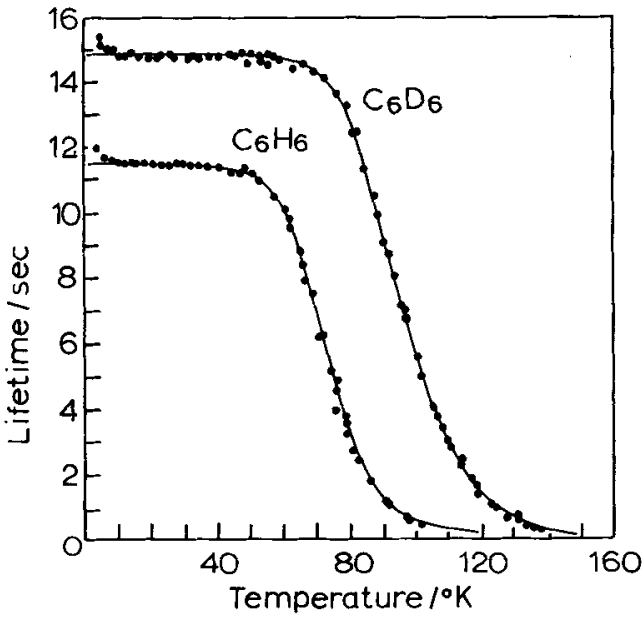

(a)

FIGURE 9. Temperature dependence of ${ }^{\tau} p$ for $\mathrm{C}_{6} \mathrm{H}_{6}$ and $\mathrm{C}_{6} \mathrm{D}_{6}$ in (a) cyclohexane and (b) cyclopentane, (Kilmer and Spangler).217 
TABLE 14. Phosphorescence lifetimes for dilute benzene solutions.

\begin{tabular}{|c|c|c|c|c|c|}
\hline $\begin{array}{l}\tau_{P} \\
(\mathrm{~s})\end{array}$ & Isomer & Solvent & $\begin{array}{l}\text { Temp. } \\
\left({ }^{\circ} \mathrm{K}\right)\end{array}$ & Remarks & $\operatorname{Ref}$. \\
\hline 7.1 & $\mathrm{C}_{6} \mathrm{H}_{6}$ & EOA & 77 & & (144) \\
\hline 17.5 & $\mathrm{C}_{6} \mathrm{H}_{6}$ & - & 20 & Two sites for decay & (171) \\
\hline 29.5 & $\mathrm{C}_{6} \mathrm{D}_{6}$ & - & 20 & This for longest & (171) \\
\hline 5.75 & $\mathrm{C}_{6} \mathrm{H}_{6}$ & 3-Methylpentane & 77 & Relaxed & $(218)$ \\
\hline 7.48 & $\mathrm{C}_{6} \mathrm{H}_{6}$ & Isopropano1 & 77 & Frozen quickly & $(218)$ \\
\hline 4.75 & $\mathrm{C}_{6} \mathrm{H}_{6}$ & Cyclohexane & 77 & Monoclinic & $(218)$ \\
\hline 12.02 & $\mathrm{C}_{6} \mathrm{D}_{6}$ & $3 M P$ & 77 & Relaxed & (218) \\
\hline 13.69 & $\mathrm{C}_{6} \mathrm{D}_{6}$ & Isopropanol & 77 & Frozen quickly & $(218)$ \\
\hline 14.10 & $\mathrm{C}_{6} \mathrm{D}_{6}$ & Cyclohexane & 77 & Monoclinic & $(218)$ \\
\hline 5.50 & $\mathrm{C}_{6} \mathrm{H}_{6}$ & $\begin{array}{l}\text { Methyl-cyclo- } \\
\text { hexane }\end{array}$ & 77 & Frozen quickly & (219) \\
\hline 6.50 & $\mathrm{C}_{6} \mathrm{H}_{6}$ & Ethano1 & 77 & Frozen quickly & $(92)$ \\
\hline 5.50 & $\mathrm{C}_{6} \mathrm{H}_{6}$ & Methanol & 77 & Frozen quick1y & $(92)$ \\
\hline 10.50 & $\mathrm{C}_{6} \mathrm{D}_{6}$ & $\begin{array}{l}\text { Methy1-cyclo- } \\
\text { hexane }\end{array}$ & 77 & Frozen quickly & (219) \\
\hline 11.20 & $\mathrm{C}_{6} \mathrm{D}_{6}$ & Ethano1 & 77 & Frozen quickly & $(92)$ \\
\hline 9.10 & $\mathrm{C}_{6} \mathrm{D}_{6}$ & Methanol & 77 & Frozen quickly & $(92)$ \\
\hline 9.83 & $\mathrm{C}_{6} \mathrm{H}_{6}$ & $\mathrm{Me}-\mathrm{cx} / \mathrm{IP}$ & $<60$ & Independent of & (213) \\
\hline 9.92 & $\mathrm{C}_{6} \mathrm{H}_{6}$ & $\begin{array}{l}\text { 3-Methylpen- } \\
\text { tane }\end{array}$ & $<60$ & temperature below & (213) \\
\hline 10.91 & $\mathrm{C}_{6} \mathrm{H}_{6}$ & EPA & $<60$ & $60^{\circ} \mathrm{K}$ but & (213) \\
\hline 11.19 & $\mathrm{C}_{6} \mathrm{H}_{6}$ & Ethanol & $<60$ & solvent dependent & (213) \\
\hline 9.0 & $\mathrm{C}_{6} \mathrm{H}_{6}$ & Dioxane & 77 & - & (214) \\
\hline
\end{tabular}


TABLE 14 (cont.)

\begin{tabular}{|c|c|c|c|c|c|}
\hline 5.90 & $\mathrm{C}_{6} \mathrm{H}_{6}$ & EPA & 77 & - & $(214)$ \\
\hline 2.0 & $\mathrm{C}_{6} \mathrm{H}_{6}$ & Cyclohexane & 77 & - & (214) \\
\hline 5.78 & $\mathrm{C}_{6} \mathrm{D}_{6}$ & Isopentane & 77 & & (212) \\
\hline 11.79 & $\mathrm{C}_{6} \mathrm{D}_{6}$ & 3-Methylpentane & 77 & & $(212)$ \\
\hline 12.11 & $\mathrm{C}_{6} \mathrm{D}_{6}$ & 3-Methylhexane & 77 & & (212) \\
\hline 11.31 & $\mathrm{C}_{6} \mathrm{D}_{6}$ & $\begin{array}{l}\text { Methy1-cyclo- } \\
\text { hexane }\end{array}$ & 77 & Constant & (212) \\
\hline 13.70 & $\mathrm{C}_{6} \mathrm{D}_{6}$ & Ethanol & 77 & values after & $(212)$ \\
\hline 13.40 & $\mathrm{C}_{6} \mathrm{D}_{6}$ & Iso-propanol & 77 & solvent & (212) \\
\hline 13.06 & $\mathrm{C}_{6} \mathrm{D}_{6}$ & EPA & 77 & relaxation & (212) \\
\hline 9.46 & $\mathrm{C}_{6} \mathrm{D}_{6}$ & Cyclohexane & 77 & & $(212)$ \\
\hline 10.32 & $\mathrm{C}_{6} \mathrm{D}_{6}$ & Isooctane & 77 & & $(212)$ \\
\hline 5.75 & $\mathrm{C}_{6} \mathrm{H}_{6}$ & 3-Methylpentane & 77 & & $(212)$ \\
\hline 8.45 & $\mathrm{C}_{6} \mathrm{H}_{6}$ & EPA & 77 & & $(212)$ \\
\hline 3.04 & $\mathrm{C}_{6} \mathrm{H}_{6}$ & $\begin{array}{l}\text { 3-Methylpentane } \\
\text { iso-pentane }\end{array}$ & 77 & & $(212)$ \\
\hline 11.44 & $\mathrm{C}_{6} \mathrm{H}_{6}$ & Cyclohexane & - & Limiting & $(217)$ \\
\hline 14.82 & $\mathrm{C}_{6} \mathrm{D}_{6}$ & Cyclohexane & - & low-temperature & (217) \\
\hline 7.46 & $\mathrm{C}_{6} \mathrm{H}_{6}$ & Cyclopentane & - & values & (217) \\
\hline 14.94 & $\mathrm{C}_{6} \mathrm{D}_{6}$ & Cyclopentane & - & & (217) \\
\hline 29.5 & $\mathrm{C}_{6} \mathrm{D}_{6}$ & Argon & 20 & & $(171,220)$ \\
\hline 14.5 & $\mathrm{C}_{6} \mathrm{D}_{6}$ & Argon & 20 & & $(171,220)$ \\
\hline 17.5 & $\mathrm{C}_{6} \mathrm{H}_{6}$ & Argon & 20 & & $(221)$ \\
\hline 0.74 & $\mathrm{C}_{6} \mathrm{H}$ & Krypton & 20 & & (221) \\
\hline
\end{tabular}


TABLE 14 (cont.)

\begin{tabular}{|c|c|c|c|c|}
\hline 0.026 & $\mathrm{C}_{6} \mathrm{H}_{6}$ & Xenon & 20 & $\overline{(221)}$ \\
\hline 29.5 & $\mathrm{C}_{6} \mathrm{D}_{6}$ & Argon & 20 & (221) \\
\hline 0.025 & $\mathrm{C}_{6} \mathrm{D}_{6}$ & Xenon & 20 & (221) \\
\hline 15.4 & $\mathrm{C}_{6} \mathrm{H}_{6}$ & $\begin{array}{l}\text { Perfluoromethy1- } \\
\text { cyclohexane }\end{array}$ & -65 & $(222)$ \\
\hline 10.9 & $\mathrm{C}_{6} \mathrm{H}_{6}$ & $\begin{array}{l}\text { Methyl-cyclo- } \\
\text { hexane }\end{array}$ & 65 & (222) \\
\hline 23.7 & $\mathrm{C}_{6} \mathrm{D}_{6}$ & $\begin{array}{l}\text { Perfluoro-cyclo- } \\
\text { hexane }\end{array}$ & -65 & (222) \\
\hline 14.3 & $\mathrm{C}_{6} \mathrm{D}_{6}$ & $\begin{array}{l}\text { Methy 1-cyc1o- } \\
\text { hexane }\end{array}$ & 65 & (222) \\
\hline 8.0 & $\mathrm{C}_{6} \mathrm{H}_{6}$ & EPA & 77 & $(148)$ \\
\hline 11.8 & $\mathrm{C}_{6}{ }_{6}{ }_{6}$ & Cyclohexane & 4.2 & (215) \\
\hline 10.2 & $\mathrm{C}_{6} \mathrm{H}_{6}$ & Borazine & 4.2 & (215) \\
\hline 9.5 & $\mathrm{C}_{6} \mathrm{H}_{6}$ & $\mathrm{C}_{6} \mathrm{D}_{6}$ & 4.2 & (215) \\
\hline 15.6 & $\mathrm{C}_{6} \mathrm{D}_{6}$ & Cyclohexane & 4.2 & (215) \\
\hline 12.5 & $\mathrm{C}_{6} \mathrm{D}_{6}$ & Borazine & 4.2 & (215) \\
\hline 6.3 & $\mathrm{C}_{6} \mathrm{H}_{6}$ & EPA & 77 & (154) \\
\hline 9.4 & $\mathrm{C}_{6} \mathrm{D}_{6}$ & EPA & 77 & (154) \\
\hline 4.6 & $\mathrm{C}_{6} \mathrm{H}_{6}$ & EPA & $77 \quad$ Monoclinic & $(207)$ \\
\hline
\end{tabular}

phosphorescence rate constant for benzene is in close agreement with that of Johnson and Ziegler (171) who deduced a value of $0.041 \mathrm{~s}^{-1}$ for $\mathrm{C}_{6} \mathrm{H}_{6}$ and $0.034 \mathrm{~s}^{-1}$ for $\mathrm{C}_{6} \mathrm{D}_{6}$. The latter authors concluded that deuteration affected the vibronic coupling necessary to promote the radiative transition and that the deuteration effect on the radiationless transition is small at variance with early theories of radiationless transitions $(201,223)$.

From the variations of $\tau_{P}$ with temperature, Kilmer and Spangler (217) concluded that the ratio $\mathrm{k}_{\mathrm{P}} \mathrm{k}_{\mathrm{ISC}} / \mathrm{k}_{\mathrm{F}}$ was independent 
of temperature and equal to $0.229 \pm 0.007 \mathrm{~s}$. Although both $\mathrm{k}_{\mathrm{F}}$ (134) and $\mathrm{k}_{\text {ISC }}$ (147) may increase with temperature above ambient, by analogy with toluene (156) and other methylated derivatives (224) it is expected that both will be nearly constant below room temperature. From a combination of these data it is clear that $k_{P}$ is independent of temperature.

A11 of the above data refer to dilute solutions; the effect of solute concentration on the phosphorescence emission yield and lifetime is very marked. At concentrations of $1 \mathrm{M}$ and above, a decrease in $\tau_{p}$ and the $x$ ratio has been reported for EPA (214), EOA (144,152), methylcyclohexane (219), and cyclohexane (207). Phosphorescence is negligible in both pure benzene crystals (225) and polycrystalline powder $(144,214)$. This has been attributed to a rapid triplet-triplet annihilation process, an explanation apparent1y confirmed by Cundal1 and Pereira (219), who detected solution some slight rather diffuse phosphorescence together with delayed fluorescence from pure benzene.

\section{$X$. THE $T_{1} \rightarrow S_{0}$ RADIATIONLESS TRANSITION}

The benzene triplet has not been observed to phosphoresce in either the gas or liquid phase, as noted previously but in view of the lifetime measured in glassy media at low temperature this is not surprising, since very small amounts of quenching impurities would reduce emission to undetectable levels. Some detailed investigations have shown that there is an intramolecular process which induces radiationless decay of the benzene triplet state, other than impurity quenching.

By competitive methods Ishikawa and Noyes (226) (sensitized biacety1 phosphorescence) and Cundall and Davies (159) (butene-2 isomerization) both estimated the triplet lifetime to be of the order of $10 \mu \mathrm{s}$. In a reexamination of the butene-2 system, Lee (227) estimated a value of $100 \mu \mathrm{s}$, a finding confirmed by Cundall and Dunnicliff (105). An examination of the kinetics of the benzene photosensitized composition of cyclopentanone decomposition allowed a value of longer than $3 \mu \mathrm{s}$ to be deduced. This type of experiment is far from satisfactory since photochemical processes can intervene at low pressures, and impurities and the quenching effects of photoproducts can affect the results. These problems can only be overcome by some form of direct measurement. Parmenter and Ring (228) used a flash method in which 20 torrs of benzene and 0.01 torr of biacetyl were submitted to a $20 \mathrm{~J}$, 3 us flash of 250 to $260 \mathrm{~nm}$ 1ight. From the time dependence of the biacetyl phosphorescence emission, a lifetime of $26 \pm 5 \mu \mathrm{s}$ was deduced. Lee (227) cites a private communication from Parmenter in which the lifetime of the gaseous triplet is given 
to be $70 \pm 20 \mu$ s for 2 torrs benzene. Burton and Hunziker (229) have developed a modulated transient absorption technique that uses $\mathrm{Hg} 6{ }^{3} \mathrm{P}_{0}$ atoms to populate the benzene triplet state. The decay of the triplet is observed by an absorption band at 231.5 $\mathrm{nm}$, assigned to the allowed ${ }^{3} \mathrm{E}_{2 \mathrm{~g}} \rightarrow{ }^{3} \mathrm{~B}_{1 \mathrm{u}}$ absorption (36), with fvalues of 0.07 and 0.06 for light and heavy benzene, respectively. The decay is pseudo-first-order, resulting from bimolecular triplet-triplet interaction. The results are viewed guardedly by other workers because of effects that may arise from the high light absorption which must be used. First order decay rates of $3 \times 10^{3} \mathrm{~s}^{-1}$ and $2 \times 10^{3} \mathrm{~s}^{-1}$ were calculated for the presençe of 300 to 800 torrs of nitrogen, needed to promote the $\mathrm{Hg} 6^{3} \mathrm{P}_{1} \rightarrow 6^{3} \mathrm{P}_{0}$ transition. The pulse radiolysis of naphthalene/benzene vapor mixtures at $390^{\circ} \mathrm{K}$ has given data which can be used to calculate $1.3 \times 10^{5} \mathrm{~s}^{-1}$ for the decay constant of the ${ }^{3} \mathrm{~B}_{1 \mathrm{u}}$ state of benzene at a partial pressure of 18 torr (230), from the naphthalene triplet absorption following irradiation.

A new experimental approach to the problem has been used by Hunter and Stock (231) involving measurement of the frequency dependence of the acoustic signal resulting from transformation of electronic excitation from vibrational to translational energy, consequent to excitation of the ${ }^{1_{B}}{ }_{2 u}$ state. This technique was used to measure the decay of the benzene triplet over the range 0 to 6 torrs, and it was found, in agreement with what could be inferred from some of the earlier work, that decay of the triplet depends upon benzene concentration. The pressure-independent decay process was found to have a rate constant of $(1.7 \pm 0.1)$ $\times 10^{3} \mathrm{~s}^{-1}$ and a collision efficiency of $1.6 \times 10^{-4}$ deduced for the second order self-quenching process. The authors claim to have discounted the effects of deactivation by traces of oxygen. A strong perturbation of the ${ }^{3} \mathrm{~B}_{1 \mathrm{l}}$ state by ground state ${ }^{1} \mathrm{~A}_{1 \mathrm{~g}}$ molecules seems the most likely mechanism for accounting for the observed concentration dependence; and involvement of the triplet excimer is in accord with the following scheme.

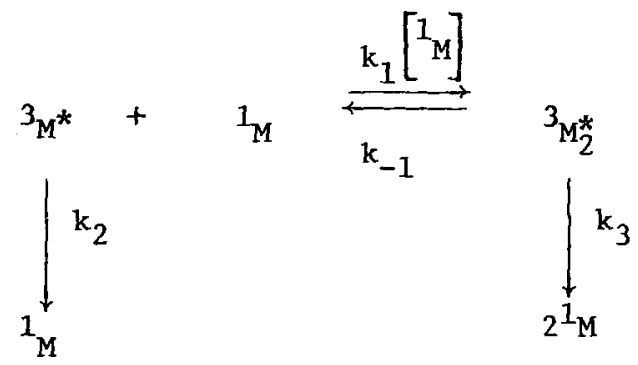


The reciprocal of the triplet lifetime ${ }^{\tau} \mathrm{T}^{-1}=\mathrm{k}_{2}+\mathrm{k}_{3}\left(\mathrm{k}_{-} \mathrm{f}^{\left.+\mathrm{k}_{3}\right)^{-1}}\right.$ $\mathrm{k}_{1}\left[{ }^{1} \mathrm{M}\right]$. Analysis of the results shows the $\mathrm{k}_{3}\left(\mathrm{k}_{-1}+\mathrm{k}_{3}\right)^{-1}$ is $1.6 \times 10^{-4}$ and thus $k_{-1} \gg k_{3}$. This contrasts with the situation in other aromatic hydrocarbons in solution where triplet-ground state interaction is proposed to explain similar shortening of measured triplet lifetime (232); in these cases, it would seem that $\mathrm{k}_{3}>\mathrm{k}_{-1}$.

The self-quenching mechanism which has been invoked for the gas phase system applies also to the liquid phase. Order of magnitude agreement between data from the various techniques for measuring $\tau_{T}$ seems to have been achieved. Cundall and Griffiths (233), obtained the first indications from studies on the benzene/ butene-2 system, that the triplet state lifetime was very short. The value for $k_{E T} \tau_{T}$ was $21.2 \mathrm{M}$ at $25^{\circ} \mathrm{C}$ where $k_{E T}$ was the overal1 rate constant for triplet excitation energy transfer from benzene to butene-2, and $\tau_{\mathrm{T}}$ the lifetime of the benzene triplet. Assuming a value of about $5 \times 10^{9} \mathrm{M}^{-1} \mathrm{~S}^{-1}$ for $\mathrm{k}_{\mathrm{ET}}, \tau_{\mathrm{T}}$ appears of the order of a few nanoseconds. Although the kinetic analysis may have oversimplified (175), the order of magnitude lifetime is similar to that determined from the work of Kaufman (234) and Hentz and Perkey (176) and also consistent with the results of Dubois $(235,236)$ who failed to detect any evidence for triplet energy transfer to biacetyl in pure benzene. By contrast, Lipsky (237), Sandros (181), and Russian workers $(238,239)$ observed triplet energy transfer from benzene to biacetyl for dilute benzene solutions. This indicates that the triplet lifetime in solution is also concentration dependent as is the case for o-xylene (240) where the lifetime increased from a few nanoseconds to microseconds or more, on dilution. This has been confirmed for benzene $(175,189)$ and further, additional evidence from photochemical (173) and pulse radiolysis (241) systems demonstrate the very short lifetime of the triplet state in pure benzene liquid. It is believed (175) that decay proceeds via the triplet excimer which is only inefficiently quenched by butene-2. Results of electron impact excitation (242) and pulse radiolysis (243) have indicated a triplet lifetime of $500 \mu \mathrm{s}$ for gaseous benzene at low and high pressures.

Attempts to directly detect the triplet state of benzene under these or similar conditions by transient spectroscopy techniques have so far been unsuccessful. Thomas and Mani (244) found a transitory species with an absorption maximum and a decay time of 112 ns in benzene and benzene cyclohexane mixtures. The results from addition of naphthalene, biacetyl, oxygen, and piperylene suggest that this is a product of reaction between triplet and ground state benzenes. Build-in times for this species, which are $3 \mathrm{~ns}$ for pure benzene and 20 ns for 10 percent benzene/cyclohexane mixture are temperature independent. Laser 
flash photolysis (179) results are consistent with a $\mathrm{T}_{1}+\mathrm{S}_{0}$ reaction for triplet decay. This is the most that has been achieved to direct observation of the benzene triplet in solution at room temperature.

The lifetime of the triplet state of benzene in fluid solutions (at room temperature and above) is determined by the, seemingly efficient, interaction of that state with ground state molecules. This is not inconsistent with the low temperature behavior from which it has been deduced (51-55), that a thermally activated $\mathrm{T}_{1} \rightarrow \mathrm{S}_{\mathrm{O}}$ transition arises from distortion of the benzene ring which destroys the strict $D_{6 h}$ symmetry. Even below $65^{\circ} \mathrm{K}$, it is apparent that hydrocarbon solvents are not inert and that perfluorocarbons are the least perturbing of possible solvents (222). The concentration quenching mechanism must involve some, as yet unestablished, form of chemical or charge transfer interaction which reduces the forbidden character of the transition. There is no positive evidence to show that this process occurs at low temperature.

\section{TRANSITIONS FROM HIGHER $(n>1)$ EXCITED STATES}

Several years ago, Braun, Kato, and Lipsky (142) showed that in the vapor solution and bulk liquids, benzene and its methylated derivatives appeared not to undergo efficient internal conversion or intersystem crossing from higher excited singlet states to form either $\mathrm{S}_{1}$ or $\mathrm{T}_{1}$ states. This was confirmed by Birks, Conte, and Walker (143) who postulated a scheme involving excimers of higher excited states, to explain their data and noted that benzene proved to be the exception amongst similar compounds in that the effect decreased on dilution.

Some more recent experimental evidence has been presented by Voltz and co-workers (145). Using 2-napthty1-2-pheny1-5oxazole-1.3 an excitation energy acceptor, these authors obtained results similar to those of Lipsky (142), but also found that autoionization occurred at wavelengths below $175 \mathrm{~nm}$. There is low efficiency of conversion of $B_{1 u}$ and $1_{E_{1 u}}$ to the ${ }^{1} B_{1 u}$ state, and relative efficiencies of fluorescence are constant but different over each of the main bands. Voltz (145) also claims that energy transfer occurs from $\mathrm{S}_{2}$ and $\mathrm{S}_{3}$ states, in agreement with Laor and Weinreb (245) but at variance with Lawson, Hirayama, and Lipsky $(72,246)$. Electron scavengers such as $\mathrm{O}_{2}$ and $\mathrm{CHCl}_{3}$ which affect the $\mathrm{S}_{3}$ and $S_{2}$ states to only a negligible extent, influences the ionization effects at higher excitation energies. 
Lawson, Hirayama, and Lipsky $(72,246)$ also measured the variation in quantum efficiencies for internal conversion from $S_{3}$ to $S_{1}$ in several solvents and found that the values vary very markedly. The efficiencies measured were 0.45 in pure benzene, 0.37 to 0.28 in alcohols and other polar solvents, 0.25 to 0.22 in aliphatic hydrocarbons, 0.04 in $n-C_{6} F_{14}$, and about zero in the gas phase. The order of effectiveness in a number of so1vents paralleled the enhancement of the $0-0$ band in absorption. The implication would seem to be that solvent perturbation produces state mixing and consequent enhancement of internal conversion $S_{n} \rightarrow S_{1}$.

other types of experiment give information about the internal conversion processes of higher excited singlet states. Lumb, Braga, and Pereira (144) measured the fluorescence and phosphorescence excitation spectra of rigid solutions of benzene in ether/isooctane/alcohol glasses at $77^{\circ} \mathrm{K}$. The two excitation spectra were identical, showing that $\phi_{\mathrm{F}}$ and $\emptyset_{\mathrm{P}}$ vary in the same manner with $\lambda_{\mathrm{ex}}$. The efficiencies of conversion from higher levels are not zero, but depend upon concentration; a surface quenching mechanism may be involved.

Direct observation of fluorescence from higher singlet states of benzene and some methyl derivatives has recently been achieved by Hirayama, Gregory, and Lipsky (247). Using apparatus capable of detecting fluorescence yields as 1 ow as $10^{-6}$ they recorded the emission spectra from oxygenated solutions of pure benzene and other aromatics excited at $184.9 \mathrm{~nm}$. Subtraction of the tail of the residual $S_{1}$ emission gives a fluorescence spectrum with $\lambda_{\max }$ approximately $235 \mathrm{~nm}$ and $\emptyset_{\mathrm{F}}=8 \times 10^{-6}$ for benzene. This is assigned to an $\mathrm{S}_{2}-\mathrm{S}_{\mathrm{o}}$ emission.

In $0.1 \mathrm{M}$ solutions of $\mathrm{p}$-xylene and mesitylene, emissions could also be detected for the $S_{3}-S_{0}$ transition. Similar successes have also been achieved with p-xylene, toluene, and mesitylene, in the vapor phase, leading to the hope that data for benzene vapor may soon be forthcoming.

Some information is available on the photochemical effects that occur after the formation of higher excited states, which may help, in part at least, to explain some of the effects. Foote, Mallon, and Pitts (248), and Shindo and Lipsky (249) investigated the photochemistry of benzene vapor, excited into the $\mathrm{S}_{3}$ state. Both sets of data, when extrapolated to zero pressure, give a quantum yield of unity for chemical reaction. The isomer formed was later (250) shown to be fulvene, with some polymer formation. This route for energy decay will be examined in the following section. 


\section{RELEVANT PHOTOCHEMICAL REACTIONS OF EXCITED STATES OF BENZENE}

As previously stated, molecular isomerization does not provide an explanation for the quantum deficit following excitation of benzene; the first band does not bear close scrutiny. However, an investigation of the photochemistry of excited benzene is of interest, in view of the variety and complexity of the isomeric products. An extensive review of conditions under which the formation of isomers of benzene and its derivatives can be found has been compiled by Scott and Jones (250). Interconversion of the isomers which would be relevant to photophysical effects are governed by orbital symmetry considerations, and examples of this type of treatment are now appearing $(251,252)$.

In 1966, Bryce-Smith and Longuet-Higgins $(65,185)$ suggested a scheme that seems to provide a generally satisfactory description of the facts. Prefulvene and Dewar-1ike intermediates consistent (184) with the symmetry of the ${ }^{1} \mathrm{~B}_{2 \mathrm{u}}$, and ${ }^{3} \mathrm{~B}_{1 \mathrm{u}}$ excited states which supposedly give rise to them, have been proposed. The existence of these intermediates has not been proven, and for heavily substituted fluoro-benzenes, Dewar isomeric forms arise from excited singlet states in apparent contravention of the symmetry considerations $(253,254)$. The significance of this is not clear.

No attempt is made here to review all the experimental data, but some investigation relevant to the theme of this article will be cited. Wilzbach, Kaplan, and Harkness (255) showed that benzene-1,3,5, $\mathrm{d}_{3}$ rearranged to the $1,2,4-i$ somer when excited at $254 \mathrm{~nm}$ in the vapor phase, and deduced that this occurred through a benzvalene intermediate with a yield of about 3 percent. Subsequently, Kaplan and Wilzbach (256) isolated benzvalene, from benzene excited within the first band, with a yield of 0.02 . Addition of added gases increases the yield by stabilization of "hot" benzvalene molecules. The data on the effect of exciting wavelength shows that relaxation from higher vibrational levels of the $S_{1}$ state is accompanied by a decrease in the yields of both fluorescence and triplet production. The work of Kaplan and Wilzbach provides some evidence for an increase in the yield of benzvalene in going from 254 to $237 \mathrm{~nm}$, but no correlation with the sharp increase in nonradiative decay when the vibrational energy exceeds $2500 \mathrm{~cm}^{-1}$ has been achieved. An interesting argument against benzvalene formation providing a complete explanation of the nonradiative processes has been advanced by Spears and Rice (111). The conservation of angular momentum must inhibit conversion of benzene into benzvalene, but no correlation of rotational energies with either radiative or 
nonradiative rate constants was found by Parmenter and Schuh (257). As pointed out in Section VIII, recent results of Stein (195) have indicated that isomerization cannot explain completely Channe1 III in benzene.

More work on the photochemistry of benzene cannot fail to be informative. A recent example of the type of experiment that shows promise is that reported by Irina and Kurien (194). Phenol and mucondialdehyde are major products found from the photolysis of benzene vapor in the presence of oxygen, and also that phenol alone is formed in the absence of oxygen on interaction with water. The experimental conditions employed a flow of the vapor through a trap, indicating that the products formed must have resulted from the interaction of a long-lived excited intermediate with water. This intermediate cannot be benzvalene since it has been established (258) that this reacts with water to give a cyclo pentadiene-1-carboaldehyde, via the following mechanism:

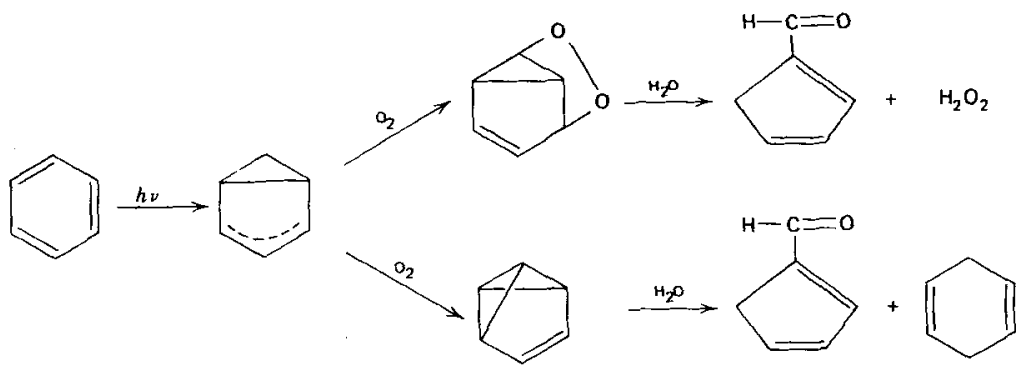

"Internal conversion" in the liquid and solid phases is still obscure. Decomposition and isomerization yields are sma11, usually of the order of 0.01 , and in general are very much less than in the gas phase, presumably due to the rapid collisional stabilization that can occur in condensed phases. Formation of an intermediate of the pre-fulvene type would require several quanta of ring-deforming vibrations, and this could account for the decrease in yields with lowering of temperature.

Since the efficiency of "internal conversion" is greater in solution than in the gas phase, and since the controlling parameters are, to a certain extent, solvent dependent $(91,94)$, the possibility of chemical reactions with solvent by excited state routes cannot be ignored. Experimental difficulties have prevented very clear results. This is illustrated by the discordant 
data on the reaction of oxygen with benzene under various conditions $(130,259-261)$.

It has been known for some time that hexatrienes can be formed by reaction of excited benzene molecules with solvent in a frozen glass $(262-264)$. Some details of the mechanism of this process have been deduced by Simons and Smith (90). They propose that intermolecular vibronic interaction with solvent is a necessary but not sufficient requirement for production of hexatrienes in viscous media. The reaction is associated with radiationless decay of the triplet state rather than a bimolecular reaction of triplet benzene with neighboring solvent molecules. Since radiationless decay constitutes intersystem crossing, the product of the reaction is also in the ground state. It is stressed by the authors that hexatrienes are not produced in fluid media or by nonphosphorescent benzene derivatives in which there is a rapid competing decay of the triplet state. The formation of the hexatriene only occurs when weak interactions occur between the relaxing triplet and the solvent.

Assignment of nonradiative decay from the $s_{1}$ state of benzene to both internal conversion and triplet formation by intersystem crossing requires that the triplet yield measurement techniques used should be reliable and that chemical reactions of excited states with triplet monitoring reagents do not occur. As a rule, in the case of olefins, which have been most used as triplet scavengers for benzene, it is reassuring to find that for the types of olefin used as triplet monitors addition products are usually only formed in very small yields $(265,268)$. Consistency with triplet yields obtained by other methods give some further confidence that the technique used, in general, provide self-consistent results.

Examples of the type of agreement are given for the gas phase in the recent review of Noyes and A1-Ani (269) and comparison of triplet yields in solution obtained by Sandros $(146,181)$ using biacety 1 as the scavenger, and Cundall et a1. (147,156,157) using butene-2.

\section{BENZENE EXCIMER}

The formation of a benzene dimer from association of a ground state monomer and an excited monomer is a well-established observation of this species was first noted by Dammers de Klerk (270) and Ivanova and co-workers (271) in a study of the effects of concentration on the fluorescence spectrum of benzene. Broad structureless emission on the long wavelength side of monomer emission at room temperature is clearly observed at concentrations 
of about 1M, and a further increasing concentration becomes the dominant component in the spectrum.

The existence of such a dimeric species, stable in the excited state, and experiencing dissociative repulsive interaction in the ground state, is explained (272) in terms of configurational interaction between excitation and charge resonance states of the dimer. Its structure is generally believed to be of an eclipsed parallel plate form, though Birks and co-workers (273275) favor a slightly displaced structure with one molecule overlapping the other. The study of Birks and Christophorou (276) has shown that the net excimer binding energy is dependent upon intermolecular separation, and it seems well established that the particular ring separation in benzene is $0.31-0.33 \mathrm{~nm}$.

The excimer so described is singlet in character, and many authors $(272,277,279)$ have suggested that emission to the repulsive ground state is dipole forbidden. It is possible (272) that a small rotation from the strict parallel plate configuration is sufficient to remove this restriction, and Chesnut et al. (280) have shown that a rotation of 30 degrees decreases the excimer binding energy by $0.01 \mathrm{eV}$. This would suggest that excimer emission probability may be temperature dependent; and such has been found to be the case by Hirayama and Lipsky (125, 281) and Cundall and Robinson (134), but not by Birks and coworkers (282).

The parameters that describe the properties of the excimer state may be extracted from kinetic analysis of transient and steady state luminescence data. The scheme due to Birks, Braga, and Lumb $(131,274)$, although criticized for its simplicity $(125,283)$, accounts well for experimental decay of the singlet excimer. The observed quantum yield of monomer fluorescence $\emptyset_{\mathrm{FM}}$ is reduced in the presence of excimer from the intrinsic yield $\emptyset_{\mathrm{FM}}^{\mathrm{O}}$ according to:

$$
\emptyset_{\mathrm{FM}}=\emptyset_{\mathrm{FM}}^{\mathrm{o}} \mathrm{c}\left(1+\mathrm{c} / \mathrm{c}_{\mathrm{h}}\right)
$$

where $1 / c_{h}$ is the Stern Volmer quenching parameter such that $\emptyset_{\mathrm{FM}}$ at $\mathrm{c} \stackrel{\mathrm{h}}{=} \mathrm{c}_{\mathrm{h}}$. A similar expression for excimer fluorescence is

$$
\emptyset_{\mathrm{FD}}=\emptyset_{\mathrm{FD}}^{\mathrm{o}}\left(1+c_{h} / \mathrm{c}\right)
$$

Two evaluations of $c_{h}$ are thus possible for all temperatures where excimer band emission can be observed. Cundall and Robinson (134) showed that the temperature of ${ }^{c} h$ led to the deduction that $\left(E_{b}+E_{I C M}-E_{I C S D}\right)=0.38 \mathrm{eV}$. (here subscripts refer to processes described in the introductory section). Excimer fluorescence lifetimes, $\tau_{D}$ can be extracted from knowledge of the measured emission lifetime of more concentrated 
solutions, and the intrinsic monomer lifetime $\tau_{M}$, according to:

$$
\tau_{\text {obs }}=\frac{\tau_{M}+\tau_{D}\left(c / c_{h}\right)}{1+c / c_{h}}
$$

Combination of this data with that of the intrinsic excimer emission yield $\emptyset_{\mathrm{FD}}^{\circ}$ allows computation of $\mathrm{k}_{\mathrm{FD}}$, the excimer fluorescence probability. Cundall and Robinson (134) found that the rate constant so calculated had an associated activation energy of 0.15 $\mathrm{eV}$, assigned to thermal distortion of the dimer to overcome dipole restrictions on the emission. Helman $(136,139)$ has found a concentration dependence for $\mathrm{k}_{\mathrm{FD}}$, and he speculates that this may be due to the formation of trimeric excited complexes.

Ludwig and Amata (135) also found it necessary to postulate the involvement of multimolecule complexes to explain some anomalies in the $\mathrm{CCl}_{4}$ quenching of emission data. There is no direct evidence for such species, though they may exist, provided the exciplex is of lower potential than the singlet monomer molecule. The binding energy for such a species would be very small. This, together with the probable highly forbidden emission, might lead to difficulties in observation. Proof of the involvement of the types of species in the decay of the excimer remains unavailable.

The excimer binding energy deduced by Gregory and Helman (136) from transient 1uminescence decay data at low temperature $(0.26 \mathrm{eV})$ is at variance with the conclusions of other authors $(125,134)(\geq 0.36 \mathrm{eV})$ using steady state luminescence data. The problem lies in determining the temperature dependence, if any, of the ratio $\mathrm{k}_{\mathrm{FD}} / \mathrm{k}_{\mathrm{FM}}$, since all authors agree that the ratio $\mathrm{k}_{\mathrm{DM}} / \mathrm{k}_{\mathrm{MD}}$ has a complete activation energy of approximately 0.25 $( \pm 0.03) \mathrm{eV}$. Theoretical estimates of Vala, Hillier, Rice and Jortner (284) and Chestnut et a1. (280) place the expected binding energy in the range 0.3 to $0.5 \mathrm{eV}$ depending upon ring separation. The various parameters describing the singlet benzene excimer are summarized in Table 15, compiled with reference to Fig. 10.

The experimental difficulties involved in measurement of fluorescence yields and lifetimes for benzene, and other systems also, as a function of concentration make it certain that the various thermodynamic quantities have not yet been firmly established.

It is reasonable to presume that the routes for decay of the excimer are similar to those available for the excited monomer. There is no direct evidence for the existence of the triplet excimer although its existence has been invoked to explain anomalous triplet yield data (175). Hillier, Glass and 


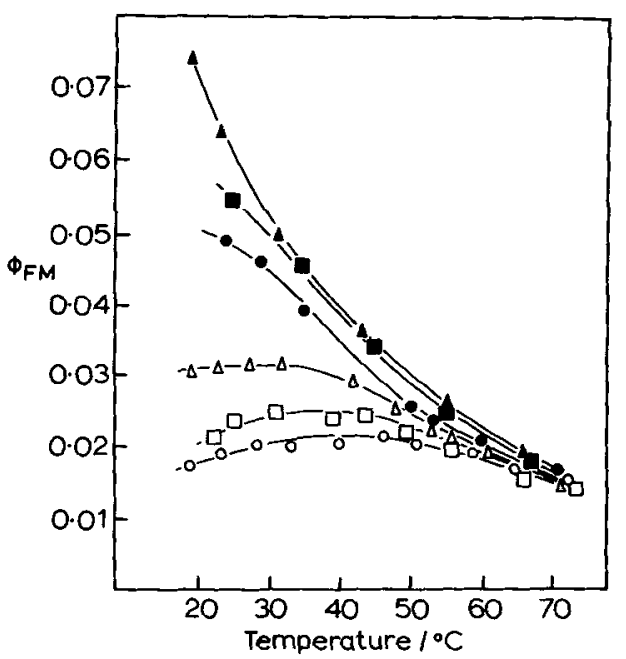

(a)

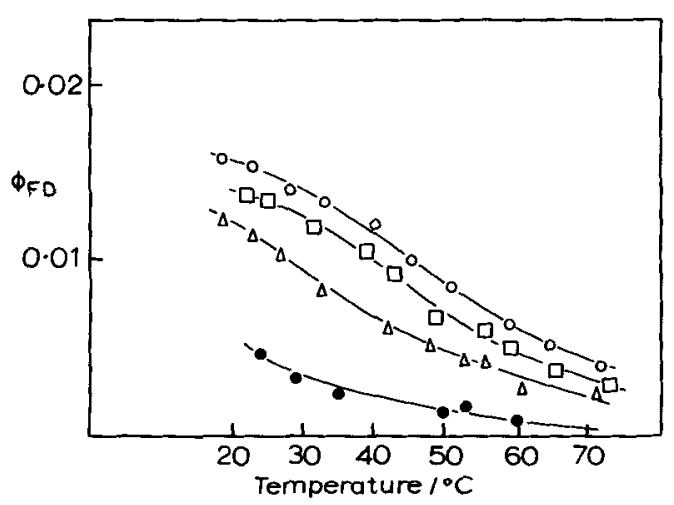

(b)

FIGURE 10. (a) Variation of monomer fluorescence yield for benzene with concentration and temperature. $\Delta, 0.12 \mathrm{M} ; 0,0.51 \mathrm{M} ; \bullet, 1.12 \mathrm{M} ; \Delta, 4.5 \mathrm{M} ; 0,7.9 \mathrm{M}$; $0,11.2 \mathrm{M}$. (b) Variation of excimer fluorescence yield with concentration and temperature. $0,11.2 \mathrm{M}$; $\mathrm{0}, 7.9 \mathrm{M} ; \Delta, 4.5 \mathrm{M} ; 0,1.12 \mathrm{M}$. 
TABLE 15. Decay parameters of the singlet excimer of benzene.

\begin{tabular}{llll}
\hline Parameter & value & $\begin{array}{l}\text { Temp. } \\
\left({ }^{\circ} \mathrm{C}\right)\end{array}$ & Comments \\
\hline$\emptyset \mathrm{FD}$ & 0.012 & 20 & Hexane \\
& 0.016 & 25 & Methylcyclohexane \\
& 0.022 & 20 & $\begin{array}{l}\text { Cyclohexane, } \\
\text { dependence }\end{array}$ \\
\hline
\end{tabular}

Ref.

$\mathrm{E}_{\mathrm{b}} \quad 0.26 \quad-30^{\circ} \mathrm{C}$ Methyl-cyclohexane

$\begin{array}{cccl} & \begin{array}{c}0.22 \\ \geq 0.36\end{array} & - & \text { Cyclohexane } \\ & 0.34 & - & \text { Methyl-cyclohexane } \\ & 4.8 & 24 & \text { Hexane } \\ 2.1 & 25 & \begin{array}{l}\text { From monomer Me-cyclohexane } \\ c_{\mathrm{h}}\end{array} \\ & 5.0 & 20 & \begin{array}{l}\text { From excimer } \\ \text { From monomer }\end{array} \\ & 16.1 & & \text { From excimer cyclohexane } \\ & 5.0 & 25 & \begin{array}{l}\text { From monomer } \\ \text { From excimer } \\ \text { (very T dependent) }\end{array}\end{array}$

\begin{tabular}{|c|c|c|c|c|}
\hline \multirow[t]{2}{*}{$\mathrm{R}_{\mathrm{m}}$} & \multirow{2}{*}{\multicolumn{2}{|c|}{$\begin{array}{l}0.46 \mathrm{eV} \\
0.48 \mathrm{eV}\end{array}$}} & & \multirow{2}{*}{$\begin{array}{l}\text { (134) } \\
(282)\end{array}$} \\
\hline & & & & \\
\hline \multirow[t]{3}{*}{$\overline{\Delta S^{\circ}}$} & -29.6 & & $\left(\mathrm{cal} \mathrm{mol}^{-1} \mathrm{~K}^{-1}\right)$ & (134) \\
\hline & -28 & & $\left(\mathrm{cal} \mathrm{mol}^{-1} \mathrm{~K}^{-1}\right.$ ) & (125) \\
\hline & -20.3 & & $\left(\right.$ cal $\mathrm{mol}^{-1} \mathrm{~K}^{-1}$ ) & (282) \\
\hline $\mathrm{E}_{\mathrm{FD}}$ & 0.145 & & $(\mathrm{eV})$ & $(134)$ \\
\hline \multirow[t]{3}{*}{$\overline{\tau_{D}}$} & 12.3 & 25 & From ionization studies & (286) \\
\hline & 12. & 20 & Hexane & (282) \\
\hline & 30 & 20 & Cyclohexane & (134) \\
\hline
\end{tabular}


Rice (287) inferred its existence from elegant experiments in which they examined the phosphorescence emission of the paracyclophane compounds. With the two benzene rings held together by methylene bridges in a sandwich structure, they observed shifted phosphorescence spectra with associated loss of structure; the most significant effects being at a ring separation of approximately $0.3 \mathrm{~nm}$. Phillips and Schug (288) identified emission at about $4.30 \mathrm{~nm}$ in $1 \mathrm{MeV}$ electron irradiated benzene at $138^{\circ} \mathrm{K}$ with the triplet excimer.

Conclusive evidence of this elusive species awaits systematic studies using transient absorption techniques. Further, the characteristic excimer emission has not been observed in the solid phase, where intermolecular distances are such as to minimize the interaction and because achievement of the necessary orientation is inhibited in the frozen samples.

\section{CONCLUSION}

It is clear that the photophysical behavior of benzene is complex and that the nonradiative $S_{1} \rightarrow S_{0}(?)$ process vaguely described at Channel III is especially important. It is not possible to conclude whether benzene is a "typica1" aromatic molecule until comparably detailed studies of other systems have been made.

\section{ACKNOWLEDGMENTS}

Part of the work presented here was completed during July of 1974 at the University of Lourenco Marques, Mozambique. We wish to express our gratitude to ULM for the hospitality and for financial support for one of us (R.B.C.) and also to NATO for a research grant. One of us (D.A.R.) gratefully acknowledges additional support from the Research and Publications Committee, ULM.

\section{REFERENCES}

(1) J. I. Steinfeld, "Molecules and Radiation", Harper and Row, New York, 1974.

(2) For example: (a) M. Goeppart-Mayer and A. L. Sklar, J. Chem. Phys., 6, 645 (1938); (b) R. C. Parr, D. P. Craig, and I. C. Ross, J. Chem. Phys., 18, 1561 (1950). 
(3) H. Sponer, G. Nordheim, A. L. Sklar, and E. Teller, J. Chem. Phys., 7, 207 (1939).

(4) J. R. Platt and H. B. Klevens, Chem. Rev., 41, 301 (1949).

(5) S. Leach, R. Lopez-Delgado, and F. Delmas, J. Mo1. Spectrosc., $\underline{7}, 304$ (1962).

(6) R. B. Merrithew and C. V. Marusak, J. Mo1. Spectrosc. 25, 269 (1968).

(7) H. C. Wolf, "Solid State Physics" (F. Seitz and D. Turnbu11, Eds.), Vo1. 9, Academic Press, New York, 1959, p. 1.

(8) J. B. Birks, "Photophysics of Aromatic Molecules", Wiley, New York, 1970.

(9) J. Koutecky, J. Cizek, J. Dubsky, and K. Hlavaky, Theoret. Chim. Acta, 2, 462 (1964).

(10) J. Koutecky, K. Hlavaky, and P. Hochman, Theor. Chim. Acta, 3, 341 (1965).

(11) J. E. Bloor, J. Lee, and S. Gartside, Proc. Chem. Soc., 413, (1960).

(12) R. J. Buenker, J. L. Whitten, and J. D. Pekke, J. Chem. Phys., 49, 261 (1968).

(13) T. Dunn and C. K. Ingold, Nature, 176, 65 (1965).

(14) S. D. Peyerinholf and R. J. Buenker, Theor. Chim. Acta, 19, 1 (1970).

(15) J. Karwowski, Chem. Phys. Lett., 18, 47 (1973).

(16) P. J. Hay and I. Shavitt, Chem. Phys. Lett., 22, 33 (1973).

(17) J. Karwowski, Acta Phys. Polon., A., 42, 655 (1972).

(18) J. N. Murre1l and T. A. Pople, Proc. Phys. Soc. (London), 69A, 245 (1956). 
(19) (a) For benzene: B. Katz, M. Brith, B. Sharf and J. Jortner, J. Chem. Phys., 52, 88 (1970); (b) Confirmed with toluene and xylene: B. Katz, M. Brith, B. Sharf and J. Jortner, J. Chem. Phys., 54, 3924 (1971); (c) E. Pantos and T. D. S. Hamilton, Chem. Phys. Lett., 17, 588 (1972).

(20) M. Brith, R. Lubert and I. T. Steinberger, J. Chem. Phys., 54, 5104 (1971).

(21) E. N. Lassettre, A. Skerbele, M. Dilton and K. Ross, J. Chem. Phys., 48, 5066 (1968).

(22) A. M. Taleb, I. H. Munro, and J. B. Birks, Chem. Phys. Lett., 21, 454 (1973).

(23) G. C. Morris and J. G. Angus, J. Mol. Spectrosc., 45, 271 (1973).

(24) B. Katz, M. Brith, B. Sharf, and J. Jortner, J. Chem. Phys., 52, 88 (1970).

(25) P. M. Johnson, J. Chem. Phys, 62, 4562 (1975).

(26) J. B. Birks, Chem. Phys. Lett., 3, 567 (1969).

(27) J. H. Callomon, J. E. Parkin, and R. Lopez-Delgado, Chem. Phys. Lett., 13, 125 (1972).

(28) G. Diesken and J. W. Moskowitz, J. Chem. Phys., 47, 3491 (1967).

(29) J. Momigny, C. Goffert and L. K'Or, Int. J. Mass. Spectrom. Ion. Phys., 1, 53 (1968).

(30) A. D. Baker, C. R. Brundle, and D. W. Turner, Int. J. Mass. Spectrom. Ion. Phys., 1, 443 (1968).

(31) E. Lindholm and B. 0. Johnson, Chem. Phys. Lett., 1, 501 (1967).

(32) B. F. Minaev, Isv. Vyssh. Vchet. Zaved. Fiz., 14, 118 (1971).

(33) L. Burnelle and M. J. Kraneppol, J. Mol. Spectrosc., 37, 383 (1971). 
(34) D. Kearns, J. Chem. Phys., 36, 1608 (1962).

(35) For summary see: S. P. McGlynn, T. Azumi and M. Kinoshita, "Molecular Spectroscopy of the Triplet State", PrenticeHa11, N.J., 1969.

(36) J. Leclerq, and J. M. Leclerq, Chem. Phys. Lett., 18, 411 (1973).

(37) R. Astier and Y. H. Meyer, Chem. Phys. Lett., 3, 399 (1968).

(38) J. B. Doering, J. Chem. Phys., 51, 2866 (1969).

(39) S. D. Colson and E. R. Bernstein, J. Chem. Phys., 43, 2661 (1965).

(40) R. M. Hochstrasser and J. E. Wesse1, Chem. Phys. Lett., 24 1 (1974).

(41) R. M. Hochstrasser, H. N. Sung and J. E. Wessel, Chem. Phys. Lett., 24, 7 (1974).

(42) I. Wunsch, H. J. Neusser and E. W. Schlag, Chem. Phys. Lett., 31, 433 (1975).

(43) J. Metcalfe, M. G. Rockley and D. Phillips, J. Chem. Soc. Faraday II, 70, 1660 (1974).

(44) M. Kasha, Disc. Faraday Soc., 9, 14 (1950).

(45) T. A. Gregory, F. Hirayama and S. Lipsky, J. Chem. Phys., 58, 4697 (1973).

(46) See also: R. B. Cundall and T. F. Palmer, Annual Reports A, Chemical Society, London, 1973.

(47) H. Schul1, J. Chem. Phys., 17, 295 (1949).

(48) G. S. Kembrovskii, V. P. Bobrovich and A. N. Serchericho, Opt. Spectrosc., 24, 213 (1968).

(49) G. N. Lewis and M. Kasha, J. Am. Chem. Soc., 66, 2100 (1944).

(50) G. W. King and E. H. Pinnington, J. Mol. Spectrosc., 15, 394 (1965). 
(51) M. S. de Groot and J. H. van der Waals, Mol. Phys., 6, 545 (1963).

(52) J. van Egmond and J. H. van der Waals, Mo1. Phys., 26, 1147 (1973).

(53) J. van Egmond and J. H. van der Waals, Mo1. Phys., 28, 457 (1974).

(54) J. van der Waals, A. M. D. Berghuis and M. S. de Groot, Mo1 Phys., 21, 497 (1971).

(55) J. van der Waals, A. M. D. Berghuis, and M. S. de Groot, Mo1. Phys., 13, 301 (1967).

(56) A. A. Gwaiz, M. A. E1-Sayed and D. S. Tinti, Chem. Phys. Lett., 9,454 (1971).

(57) D. M. Haaland and G. C. Nieman, J. Chem. Phys., 59, 4435 (1973).

(58) C. C. Nieman and D. S. Tinti, J. Chem. Phys., 46, 1432 (1967).

(59) D. M. Burland, G. Castro and G. W. Robinson, J. Chem. Phys., 52, 4100 (1970).

(60) A. Devaquet, J. Am. Chem. Soc., 94, 9013 (1972).

(61) Y. Fujimura, H. Yanaguchi and T. Nakajima, Bul1. Chem. Soc. Japan, 45, 304 (1972).

(62) A. D. Liehr, J. Phys. Chem., 67, 389 (1963).

(63) D. Bryce-Smith, A. Gilbert and D. A. Robinson, Angew. Chem., 83, 803 (1971).

(64) E. E. van Tamlen and S. P. Pappas, J. Am. Chem. Soc., 85, 3297 (1963).

(65) D. Bryce-Smith and H. C. Longuet-Higgins, Chem. Commun., 593 (1966).

(66) G. V. Klimusheva, Teor. Khim. Akad. Nauk. SSSR., 2, 37-43 (1966). 
(67) For brief reviews see: (a) B. Linder and S. Abdulnur, J. Chem. Phys., 54, 1807 (1971). (b) J. B. Birks, ref. 8. pp. 109-119.

(68) For brief review of observable effects of Davydoy splitting, see: H. Suzuki, "Electronic Absorption Spectra and Geometry of Organic Molecules", Academic Press, New York, 1967, pp. 112-113.

(69) Three of the components are allowed and are easily observed (see ref. 68); the fourth factor group is forbidden but has also been observed: S. D. Colson, J. Chem. Phys., 44, 3324 (1968).

(70) J. W. Eastman and S. J. Rehfeld, J. Phys. Chem., 74, 1438 (1970) .

(71) For a description of the simple theory and an account of deviations noted for benzene, see ref. 68, pp. 100-101.

(72) C. W. Lawson, F. Hirayama and S. Lipsky, J. Chem. Phys., 51, 1590 (1969).

(73) J. S. Ham, J. Chem. Phys., 21, 756 (1953).

(74) N. S. Bayliss and L. Hulme, Austra1. J. Chem., 6, 257 (1953).

(75) Y. Kanda, Y. Gondo and R. Shimada, Spectrochim. Acta, 17, 424 (1961).

(76) N. S. Bayliss and N. W. Cant, Spectrochim. Acta, 18, 1287 (1962).

(77) J. R. Platt, J. Mo1. Spectrosc. 9, 288 (1962.

(78) R. Pariser, J. Chem. Phys., 24, 250 (1956).

(79) N. S. Ham and K. Ruedenberg, J. Chem. Phys., 25, 1 (1956).

(80) G. W. Robinson, J. Chem. Phys., 46, 572 (1967).

(81) M. Koyanagi and Y. Kanda, Spectrochim. Acta, 20, 993 (1964).

(82) G. Durocher and C. Sandorfy, J. Mo1. Spectrosc. 14, 400 (1964). 
(83) G. Durocher and C. Sandorfy, J. Mo1. Spectrosc., 20, 410 (1966).

(84) M. Koyanagi, J. Mo1. Spectrosc., 25, 273 (1968).

(85) N. S. Bayliss, J. Mol. Spectrosc., 31, 406 (1969).

(86) A. Trombeti and C. Zauli, J. Chem. Soc., (B), 1968, 15741577.

(87) Y. Munakami and Y. Kanda, Bu11. Chem. Soc. Japan 41, 2599 (1968).

(88) N. C. Perrins, J. P. Simons and A. L. Smith, Trans. Faraday Soc., 67, 3415 (1971).

(89) J. P. Simons and A. L. Smith, J. Chem. Soc. Faraday II., 70, 53 (1974).

(90) J. P. Simons and A. L. Smith, Chem. Phys. Lett., 16, 536 (1972); ibid., 25, 97 (1974).

(91) R. B. Cundall and L. C. Pereira, Chem. Phys. Lett., 18, 371 (1973).

(92) R. B. Cunda11, and L. C. Pereira, submitted for publication.

(93) L. C. Pereira, Ph.D. Thesis, University of Nottingham (1972).

(94) M. Luria, M. Ofran and G. Stein, J. Phys. Chem., 78, 1904 (1974).

(95) D. A. Robinson, Unpub1ished results.

(96) R. B. Cundall and A. J. Harrison, To be published.

(97) C. S. Parmenter, Adv. Chem. Phys., 22 (1972).

(98) C. S. Parmenter and M. W. Schuyler, J. Chem. Phys., 52, 5366 (1970).

(99) C. S. Parmenter and M. W. Schuyler, Chem. Phys. Lett., 6, 339 (1970).

(100) J. A. Poole, J. Phys. Chem., 69, 1343 (1965). 
(101) A. E. Douglas and C. W. Matthews, J. Chem. Phys., 48, 4788 (1968).

(102) E. M. Anderson and G. B. Kistiakowsky, J. Chem. Phys., 48, 4787 (1968).

(103) W. A. Noyes, Jr., W. A. Mulac and D. A. Harter, J. Chem. Phys., 44, 2100 (1966).

(104) E. M. Anderson and G. B. Kistiakowsky, J. Chem. Phys., 51, 182 (1969).

(105) K. Dunnicliff, Ph.D. Thesis, University of Nottingham (1971): R. B. Cunda1l and K. Dunnicliff, To be published.

(106) A. S. Abramson, K. G. Spears and S. A. Rice, J. Chem. Phys., 56, 2291 (1972).

(107) (a) G. M. Breuer and E. K. C. Lee, J. Chem. Phys., 51, 3130 (1969); (b) G. M. Breuer and E. K. C. Lee, J. Chem. Phys., 51, 3615 (1969).

(108) T. Chen and E. W. Schlag, "Molecular Luminescence" (E. C. Lim, Ed.), W. A. Benjamin, New York, 1969, p. 381.

(109) M. Nishikawa and P. K. Ludwig, J. Chem. Phys., 52, 107 (1970).

(110) G. S. Burton and H. E. Hunziker, J. Chem. Phys., 52, 3302 $(1970)$.

(III) K. G. Spears and S. A. Rice, J. Chem. Phys., 55, 5561 (1971).

(112) B. K. Selinger and W. R. Ware, J. Chem. Phys., 53, 3160 (1970).

(113) W. R. Ware, B. K. Selinger, C. S. Parmenter and M. W. Schuyler, Chem. Phys. Lett., 6 , 342 (1970).

(114) J. R. Lockwood, Ph.D. Thesis, Nottingham (1974).

(115) B. K. Selinger and W. R. Ware, J. Chem. Phys., 52, 5482 (1970).

(116) R. B. Cunda11, K. Dunnicliff and A. J. R. Voss., Joint Ann. Mtg. Chem. Soc. and R.I.C., Nottingham, April 1969. 
(117) S. J. Strickler and R. J. Watts, J. Chem. Phys., 44, 5366 (1970).

(118) G. B. Kistiakowsky and C. S. Parmenter, J. Chem. Phys., 42, 2942 (1965).

(119) R. B. Cunda11 and L. C. Pereira, J. Chem. Soc. Faraday II, 68, 1152 (1972).

(120) J. W. Eastman, J. Chem. Phys., 49, 4617 (1968).

(121) M. D. Lumb and M. I. Barradas, L. C. Pereira and C. L. Braga, Rev. Fiz. Quin. Eng. U.L.M., 1, 1 (1969).

(122) G. B. Evans, Ph.D. Thesis, Nottingham (1968).

(123) W. R. Dawson and M. W. Windsor, J. Phys. Chem., 72, 325 (1968).

(124) M. D. Lumb and D. A. Weyl, J. Mo1. Spectrosc., 23, 365 (1967).

(125) F. Hirayama and S. Lipsky, J. Chem. Phys., 51, 1939 (1969).

(126) I. B. Berlman, "Handbook of Fluorescence Spectra of Aromatic Molecules", Academic Press, New York, 1971.

(127) R. B. Cundall, S. McD. Ogilvie, and D. A. Robinson, J. Photochem., 1, 417 (1973/1974).

(128) C. A. Parker, Anal. Chem., 34, 502 (1962).

(129) M. Luria and G. Stein, J. Phys. Chem., 76, 165 (1972).

(130) K. Kaplan, L. A. Wendling and K. E. Wilzbach, J. Am. Chem. Soc., 93, 3819 (1971).

(131) J. B. Birks, C. L. Braga and M. D. Lumb, Proc. Roy. Soc., A 283, 83 (1965).

(132) T. V. Ivanova, G. A. Mokeeva and B. Ya. Sveshnikov, Opt. Spectrosc., 12, 325 (1962); T. V. Ivanova, P. I. Kudryashev, and B. Ya. Sveshnkov, Sov. Phys. Dok1., 6, 407 (1961). 
(133) M. D. Lumb, Private communication, 1971.

(134) R. B. Cunda11 and D. A. Robinson, J. Chem. Faraday II, 68, 1133 (1972).

(135) P. K. Ludwig and C. D. Amata, J. Chem. Phys., 49, 326 (1968).

(136) T. A. Gregory and W. P. Helman, J. Chem. Phys., 56, 377 (1972).

(137) J. R. Greenleaf and T. A. King, Proc. Int, Conf. Luminescence, Budapest, 212 (1968).

(138) P. M. Froehlich and H. A. Morrison, J. Phys, Chem., 76, 3566 (1972).

(139) W. P. Helman, J. Chem. Phys., 51, 354 (1969).

(140) See, for example, ref. 86, 119.

(141) S. Kato, S. Lipsky, and C. L. Braun, J. Chem. Physics, 37, 190 (1962).

(142) C. L. Braun, S. Kato and S. Lipsky, J. Chem. Phys., 39, 1645 (1963).

(143) J. B. Birks, J. C. Conte and G. Walker, J. Phys. B, I, 934 (1968).

(144) M.D. Lumb, C. L. Braga and L. C. Pereira, Trans. Faraday Soc., 65, 1992 (1969).

(145) C. Fuchs, F. Heissel and R. Voltz, J. Phys. Chem., 76, 3867 (1972).

(146) K. Sandros, Acta Chem. Scand., 25, 3651 (1971).

(147) R. B. Cunda11 and D. A. Robinson, J. Chem. Soc. Faraday II 68,1145 (1972).

(148) C. A. Parker and C. C. Hatchard, Analyst, 87, 664 (1962).

(149) E. H. Gilmore, G. E. Gibson and D. S. McClure, J. Chem. Phys., 20, 829 (1952); ibid, 23, 399 (1955). 
(150) E. C. Lim, J. Chem. Phys., 36, 3497 (1962).

(151) M. D. Lumb and A. 0. A1 Chalabi, Chem. Phys. Lett., 11, 365 (1971).

(152) M. D. Lumb and L. C. Pereira, "Organic Scintillators and Liquid Scintillation Counting" (D. L. Horrocks and C. Peng, Eds.), Academic Press, New York, 1971, p. 239.

(153) E. C. Lim, Private Communication, cited in D. M. Haaland and G. C. Nieman, J. Chem. Phys., 59, 1013 (1973).

(154) R. Li and E. C. Lim, J. Chem. Phys., 57, 605 (1972).

(155) S. F. Fischer and E. C. Lim, Chem. Phys. Lett., 14, 40 (1972).

(156) R. B. Cunda11, L. C. Pereira and D. A. Robinson, J. Chem. Soc. Faraday II, 69, 701 (1973).

(157) R. B. Cundall and L. C. Pereira, Chem. Phys. Lett., 16, 371 (1972).

(158) R. B. Cundall and S. Mc. Ogilvie, To be published, 1976.

(159) R. B. Cunda11 and A. S. Davies, Trans. Faraday Soc., 62, 1151 (1966).

(160) W. A. Noyes, Jr., and D. A. Harter, J. Chem. Phys., 46, 674 (1967).

(161) S. Y. Ho and W. A. Noyes, Jr., J. Am. Chem. Soc., 89, 5091 (1967).

(162) H. O. Denschlag and E. K. C. Lee, J. Am. Chem. Soc., 90, 3628 (1968).

(163) K. Nakamura, J. Am. Chem. Soc., 93, 3138 (1971).

(164) G. C. Nieman and G. W. Robinson, J. Chem. Phys., 39, 1298 (1963).

(165) S. D. Colson and G. W. Robinson, J. Chem. Phys., 48, 2550 (1968).

(166) F. M. Garforth, G. K. Ingold and H. G. Poole, J. Chem. Soc., 491 (1948). 
(167) E. R. Bernstein, S. D. Colson, D. S. Tinti and G. W. Robinson, J. Chem. Phys., 48 (1968); G. Nonnemacher and R. Mecke, Spectrochim. Acta, $\overline{17}, 1049$ (1961).

(168) F. Langenbucher and R. Mecke, Spectrochim. Acta, 21, 1287 (1965).

(169) A. R. Gee and G. W. Robinson, J. Chem. Phys., 46, 4847 (1967).

(170) J. W. Rabalais, H. J. Maria and S. P. McGlynn, J. Chem. Phys., 51, 2259 (1969).

(171) P. M. Johnson and L. Ziegler, J. Chem. Phys., 56, 2169 (1972).

(172) G. S. Hammond and A. A. Lamola, Unpublished, cited in "Photochemistry", J. G. Calvert and J. N. Pitts, Jr., Wiley, New York, 1966.

(173) R. B. Cunda11 and W. Tippett, Trans. Faraday Soc., 6ㅁ, 350 (1970).

(174) R. R. Hentz and H. G. A1tmiller, J. Phys. Chem., 74, 2646 (1970).

(175) R. B. Cundall and D. A. Robinson, J. Chem. Soc. Faraday II, 68, 1691 (1972).

(176) R. R. Hentz and L. M. Perkey, J. Phys. Chem., 74, 3047 (1970).

(177) R. R. Hentz and R. M. Thibault, J. Phys. Chem., 77, 1105 (1973).

(178) R. B. Cunda11, L. C. Pereira, and D. A. Robinson, Chem. Phys. Lett., 13, 253 (1972).

(179) R. V. Bensasson, J. T. Richards, and J. K. Thomas, Chem. Phys. Lett., 9, 13 (1971).

(180) V. M. Berenfel'd and V. A. Krongauz, Izn. Akad. Nauk. SSSR Sen. Fiz., 32 (9), 1575 (1968).

(181) K. Sandros, Acta Chem. Scand., 23, 2815 (1969).

(182) D. A. Robinson, Ph.D. Thesis, University of Nottingham (1971). 
(183) See also J. B. Birks, ref. 8, p. 172.

(184) See, for example: I. Jano and Y. Mori, Chem. Phys. Lett., 2, 185 (1968).

(185) D. Bryce-Smith, Pure Appl. Chem., 16, 47 (1968).

(186) I. Jano, Chem. Phys. Lett., 2, 205 (1968).

(187) See, for example: (a) K. E. Wilzbach, L. Kaplan and A. L. Harkness, J. Am. Chem. Soc., 90, 1116 (1968); L. Kaplan and K. E. Wilzbach, J. Am. Chem. Soc., 90, 3291 (1968).

(188) R. B. Cunda11, D. A. Robinson and A. J. R. Voss, J. Photochem., 2, $239(1973 / 1974)$.

(189) A. J. R. Voss, Ph.D. Thesis, Nottingham (1969).

(190) J. B. Birks, Organic Molecular Photophysics, Vol. I, Wiley, New York (1974).

(191) A. A. Lamola, G. S. Hammond and F. B. Mallory, Photochem. Photobiol., 4, 259 (1965).

(192) D. Phillips, J. Lemaire, C. Burton and W. A. Noyes, Jr., Adv. Photochem., 5, 329 (1968).

(193) G. Stein, Private communication.

(194) J. Irina and K. C. Kurien, Chem. Commun., 1973, 739.

(195) H. Lutz and G. Stein, J. Phys. Chem., 78, 1909 (1974) and references therein.

(196) See, for example: R. B. Cundall and S. McD. Ogilvie, "Organic Molecular Photophysics:, Vol. II, Wiley, New York (1974).

(197) Y. Ilan and G. Stein, Chem. Phys. Lett., 31, 441 (1975).

(198) S. J. Formosinho, J. Chem. Soc. Faraday II, 70, 605 (1974);

S. J. Formosinho and J. Dias da Silva, Mo1. Photochem., $6(4), 409(1974)$.

(199) R. E. Kellogg and R. G. Bennett, J. Chem. Phys., 41, 3942 (1964). 
(200) W. Siebrand and D. F. Williams, J. Chem. Phys., 46, 403 (1967).

(201) W. Siebrand, "The Triplet State" (A. B. Zahlan, Ed.), Cambridge University Press, 1967.

(202) M. J. Shinitsky, J. Chem. Phys., 56, 5979 (1972).

(203) A. H. Kalantar, J. Chem. Phys., 48, 4992 (1968).

(204) M. Almgren, Photochem. Photobiol., 8, 231 (1968).

(205) E. D. Cehelnik, K. D. Mielenz and R. A. Velapoidi, J. Res. NBS, 79A, 1 (1975).

(206) T. E. Martin and A. H. Kalantar, J. Chem. Phys., 50, 1486 (1969).

(207) J. D. Spangler and N.G. Kilmer, J. Chem. Phys., 48, 698 (1968).

(208) T. E. Martin and A. H. Kalantar, J. Chem. Phys., 49, 244 (1968).

(209) T. E. Martin and A. H. Kalantar, J. Phys. Chem., 74, 2030 (1970).

(210) A. Bernas and T. B. Truong, Photochem. Photobio1., 15, 311 (1972).

(211) J. H. Leubner, J. Phys. Chem., 73, 2088 (1969).

(212) T. E. Martin and A. H. Kalantar, J. Phys. Chem, , 72, 2265 (1968).

(213) J. H. Leubner, J. Phys. Chem., 74, 77 (1970); J. H. Leubner and J. E. Hodgkins, J. Phys. Chem., 73, 2545 (1969).

(214) F. Hirayama, J. Chem. Phys., 42, 3726 (1965).

(215) G. F. Hatch, M. D. Er1itz and G. C. Nieman, J. Chen. Phys., 49, 3723 (1968); E. C. Lim, Ed., "Molecular Luminescence", W. A. Benjamin, New York, 1969.

(216) A. C. Ling and J. E. Willard, J. Phys. Chem., 72, 1918 (1968). 
(217) N. G. Kilmer and J. D. Spangler, J. Chem. Phys., 54, 604 (1971).

(218) T. E. Martin and A. H. Kalantar, J. Chem. Phys., 48, 4996 (1968).

(219) R. B. Cunda11 and L. C. Pereira, Chem. Phys. Lett., 29, 561 (1974).

(220) P. M. Johnson and M. C. Studez, Chem. Phys. Lett., 18, 371 (1973).

(221) Yei-Ping Hsu and P. M. Johnson, J. Chem. Phys., 59, 136 (1973).

(222) D. M. Haaland and G. C. Nieman, J. Chem. Phys., 59, 1013 (1973).

(223) G. W. Robinson, J. Chem. Phys., 47, 1967 (1967), and references therein.

(224) S. McD. Ogilvie, Ph.D. Thesis, University of Nottingham, (1974).

(225) H. Sternlicht, G. C. Nieman and G. W. Robinson, J. Chem. Phys., 38, 1326 (1963).

(226) H. Ishikawa and W. A. Noyes Jr., J. Chem. Phys., 37, 583 (1962).

(227) E. K. C. Lee, H. O. Denschlag, and G. A. Hanniger, Jr., J. Chem. Phys., 48, 4547 (1968).

(228) C. S. Parmenter and B. L. Ring, J. Chem. Phys., 46, 1198 (1967).

(229) C. S. Burton and H. E. Hunziker, Chem. Phys. Lett., 6 , 352 (1970).

(230) M. Nishikawa and M. C. Sauer, J. Chem. Phys., 51, 1 (1969).

(231) T. F. Hunter and M. G. Stock, Chem. Phys. Lett., 22, 368 (1973); T. F. Hunter and M. G. Stock, J. Chem. Soc.

Faraday II (1974). 
(232) J. Langelaar, G. Jansen, R. P. H. Rettschnick, and G. J. Hoytink, Chem. Phys. Lett., 12, 86 (1971).

(233) R. B. Cunda11 and P. A. Griffiths, Disc. Faraday Soc., 36, 111 (1963); Trans. Faraday Soc., 61, 1968 (1965).

(234) R. G. Kaufman, Disc. Faraday Soc., 36, 262 (1963).

(235) J. T. Dubois and F. Wilkinson, J. Chem. Phys., 38, 2541 (1963); ibid., 39, 377 (1963).

(236) J. W. van Loben Sels and J. T. Dubois, J. Chem. Phys., 45, $1522(1966)$.

(237) S. Lipsky, J. Chem. Phys., 38, 2786 (1963).

(238) I. A. Lisovska, M. D. Sakharova and I. C. Kaplan, Optics Spectrosc., 23, 348 (1967).

(239) V. A. Krongauz, Dok1. Akad. Nauk SSSR, 155, 658 (1964).

(240) R. B. Cunda11 and A. J. R. Voss, Chem. Commun., 1969, 116 (1969); R. B. Cunda11. D. A. Robinson and A. J. R. Voss, J. Photochem., 2, 234 (1973/1974).

(241) R. B. Cunda11, G. B. Evans and J. P. Keene, J. Phys. Chem. 72, 3871 (1968).

(242) K. C. Smyth, J. A. Schiavone and R. S. Freund, J. Chem. Phys., 61, 1789 (1974).

(243) Y. Hatano, S. Takao and T. Veno, Chem. Phys. Lett., 30 , 429 (1975).

(244) J. K. Thomas and J. Mani, J. Chem. Phys., 51, 1834 (1969).

(245) V. Laor and A. Weinreb, J. Chem. Phys., 43, 1565 (1965).

(246) C. W. Lawson, F. Hirayama and S. Lipsky, in: "Molecular Luminescence", (E. C. Lim, Ed.), W. A. Benjamin, New York, 1969, p. 837.

(247) F. Hirayama, T. A. Gregory and S. Lipsky, J. Chem. Phys., 58, $4886(1973)$. 
(248) J. K. Foote, M. H. Mallon and J. N. Pitts, Jr., J. Am. Chem. Soc., 88, 3698 (1966).

(249) K. Shindo and S. Lipsky, J. Chem. Phys., 45, 2292 (1966).

(250) L. F. Scott and M. Jones, Jr., Chem. Rev., 72, 181 (1972).

(251) P. Lechtken, R. Breslaw, A. H. Schmidt, and N. J. Turro, J. Am. Chem. Soc., 95, 3025 (1973).

(252) C. A. Renner, T. J. Katz, J. Pouliquen, N. J. Turro and W. H. Wadde11, J. Am. Chem. Soc., 97, 2568 (1975).

(253) G. Camoggi, F. Gozzo and C. Cevidal1i, Chem. Commun., $1966,313$.

(254) G. P. Semeluk and R. S. Stevens, Chem. Commun., 1970, 1720.

(255) K.E. Wilzbach, L. Kaplan and A. L. Harkness, J. Am. Chem. Soc., 90, 1116 (1968).

(256) L. Kaplan and K. E. Wilzbach, J. Am. Chem. Soc., 90, 3291 (1968).

(257) C. S. Parmenter and M. D. Schuh, Chem. Phys. Lett., 13, 120 (1972).

(258) J. Irina and K. C. Kurien, Chem. Ind., 1972, 763.

(259) K. Wei, J. C. Mari and J. N. Pitts, Jr., J. Am. Chem. Soc., 89, 4225 (1967).

(260) C. Farenhorst, Tetrahedron Lett., 4835 (1968).

(261) M. Luria and G. Stein, Chem. Commun., 1970, 1650.

(262) E. Migirdicyan, J. Chem. Phys., 63, 520 (1966); ibid., 63, 535 (1966).

(263) S. Leach, J. Chem. Phys., 55, 719 (1958).

(264) E. J. Anderson, H. I. J. Chilton and G. Porter, Proc. Chem. Soc., 1960, 352 .

(265) K. E. Wilzbach and L. Kaplan, J. Am. Chem. Soc., 88, 2066 (1966). 
(266) J. Cornelisse, V. Y. Merritt and R. Srinivasan, J. Amer. Chem. Soc., 95, 6197 (1973).

(267) W. Tippett, Ph.D. Thesis, University of Nottingham (1968).

(268) D. Bryce-Smith, A. Gilbert, B. Orger and H. Tyrell, Chem. Commun., 1974, 334 .

(269) W. A. Noyes, Jr., and K. A1-Ani, Chem. Rev., 74, 29 (1974).

(270) A. Dammers-de-Klerk, Mo1. Phys., 1, 141 (1958).

(271) T. V. Ivanova, G. A. Mokeeva and B. Ya. Sveshukov, Opt. Spectros., 12, 325 (1962).

(272) E. Konijnenberg, Ph.D. Thesis, University of Amsterdam (1963).

(273) J. B. Birks, A. A. Kazzaz, and T. A. King, Proc. Roy. Soc., A291, 556 (1966).

(274) J. B. Birks, "Progress in Reaction Kinetics", (G. Porter, Ed.), Vol. 5, Pergammon, New York, 1970, p. 263.

(275) B. L. Barnes and J. B. Birks, Proc. Roy. Soc., A291, 570 (1966).

(276) J. B. Birks and L. G. Christophorou, Proc. Roy Soc., A277, 571 (1964).

(277) J. Amuzumi and H. Azumi, Bul1. Chem. Soc. Japan, 39, 2317 (1966).

(278) A. K. Chandra and E. C. Lim, J. Chem. Phys., 48, 2589 (1968); ibid, 49 , 5066 (1968).

(279) A. K. Chandra, Chem. Phys. Lett., 5, 229 (1970).

(280) D. B. Chestnut, C. J, Fritchie and H. E. Simmons, J. Chem. Phys., 42, 1127 (1965).

(281) F. Hirayama and S. Lipsky, in: "Molecular Luminescence", (E. C. Lim, Ed.), W. A. Benjamin, New York, 1969.

(282) J. R. Greenleaf, M. D. Lumb and J. B. Birks, J. Phys. B., 1, 1157 (1968). 
(283) Y. Yguerabide, J. Chem. Phys., 49, 1018 (1968).

(284) M. T. Vala, I. H. Hillier, S. A. Rice and J. Jortner, J. Chem. Phys., 49, 326 (1966).

(285) M. D. Lumb, Private communication, 1971.

(286) L. G. Christophorou, J. G. Carter and M. E. M. Abu-Zeid, J. Chem. Phys., 49, 3775 (1968).

(287) I. H. Hillier, L. Glass and S. A. Rice, J. Chem. Phys., 45, 3015 (1966).

(288) D. H. Phillips and J. C. Schug, J. Chem. Phys., 50, 3297 (1969). 